\title{
WHAT EARS DO FOR BATS: A COMPARATIVE STUDY OF PINNA SOUND PRESSURE TRANSFORMATION IN CHIROPTERA
}

\author{
MARTIN K. OBRIST ${ }^{1}$,*, M. BROCK FENTON ${ }^{1}$, JUDITH L. EGER ${ }^{2}$ \\ and PETER A. SCHLEGEL ${ }^{3}$ \\ ${ }^{1}$ Department of Biology, York University, North York, Ontario, Canada M3J 1P3, \\ ${ }^{2}$ Royal Ontario Museum, Department of Mammalogy, 100 Queens Park, Toronto, \\ Ontario, Canada, M5S 2 C6 and ${ }^{3}$ Zoologisches Institut, Luisenstrasse 14, \\ D-8000 München 2, Germany
}

Accepted 29 March 1993

\begin{abstract}
Summary
Using a moveable loudspeaker and an implanted microphone, we studied the sound pressure transformation of the external ears of 47 species of bats from 13 families. We compared pinna gain, directionality of hearing and interaural intensity differences (IID) in echolocating and non-echolocating bats, in species using different echolocation strategies and in species that depend upon prey-generated sounds to locate their targets. In the Pteropodidae, two echolocating species had slightly higher directionality than a non-echolocating species. The ears of phyllostomid and vespertilionid species showed moderate directionality. In the Mormoopidae, the ear directionality of Pteronotus parnellii clearly matched the dominant spectral component of its echolocation calls, unlike the situation in three other species. Species in the Emballonuridae, Molossidae, Rhinopomatidae and two vespertilionids that use narrow-band search-phase echolocation calls showed increasingly sharp tuning of the pinna to the main frequency of their signals. Similar tuning was most evident in Hipposideridae and Rhinolophidae, species specialized for flutter detection via Doppler-shifted echoes of high-duty-cycle narrowband signals. The large pinnae of bats that use prey-generated sounds to find their targets supply high sound pressure gain at lower frequencies. Increasing domination of a narrow spectral band in echolocation is reflected in the passive acoustic properties of the external ears (sharper directionality). The importance of IIDs for lateralization and horizontal localization is discussed by comparing the behavioural directional performance of bats with their bioacoustical features.
\end{abstract}

\section{Introduction}

Next to wings, the external ears or pinnae are among the most conspicuous features of many species of bats, the members of the mammalian order Chiroptera. There are at least

\footnotetext{
*Present address: Swiss Federal Institute for Forest, Snow and Landscape Research, CH-8903 Birmensdorf, Switzerland.

Key words: pinna properties, directionality, echolocation, Chiroptera, bats, hearing.
} 
three reasons why the Chiroptera offer excellent possibilities for examining the role of the external ear in acoustic behaviour. First, there are echolocating and non-echolocating bats. Although it is tempting to associate the echolocation abilities of bats with the features of their ears, echolocation is well-developed and widespread in the Microchiroptera, but not in the Megachiroptera. Second, echolocation is a trait of the Microchiroptera but not all species use the same approach to echolocation and some do not depend upon echolocation to find their prey (Neuweiler and Fenton, 1988). Third, among the Microchiroptera some species have large and conspicuous pinnae (e.g. Megadermatidae, Nycteridae, some Phyllostomidae and some Vespertilionidae) while others have smaller, less conspicuous ones (e.g. many Emballonuridae, Vespertilionidae and Molossidae).

In the Microchiroptera, we know of four basic approaches to echolocation (Neuweiler and Fenton, 1988). The first three involve the use of echolocation for detecting and tracking targets: (1) species producing relatively short, broad-band echolocation calls at low duty cycle $(<20 \%)$ when searching for prey; (2) species with low duty-cycles $(<20 \%)$ using longer calls of narrower bandwidth; and (3) the flutter detectors or constant-frequency (CF) bats producing long, narrow-band signals at high duty-cycle $(>80 \%)$. The fourth approach involves species that may echolocate but usually use preygenerated cues to find their targets. These four approaches occur in several families of Microchiroptera, suggesting that they are polyphyletic.

The physical effects of sound propagation in air (Lawrence and Simmons, 1982) make echolocation a rather short-range orientation system (Kick, 1982). Bat's acoustic receivers, including their pinnae, are one central component in maximizing the distance over which they can hear. Call features are another, but increasing call strength also makes the echolocator more conspicuous to potential prey (Roeder, 1970), to conspecifics (Balcombe and Fenton, 1988) and to predators (Fenton, 1980). Large external ears also contribute to low auditory thresholds in some microchiropteran bats (e.g. $<0 \mathrm{~dB}$ SPL in Megaderma lyra, Schmidt et al. 1984, and Rhinolophus ferrumequinum, Long and Schnitzler, 1975). In echolocation, sound production and reception should be matched to the physical properties of the acoustic waves. Guppy and Coles (1988a) showed a correlation between the wavelength of sonar signals and pinna dimensions in some rhinolophid and hipposiderid bats, high-duty-cycle species specialized for high, narrow-band frequencies; they found a similar trend in the Molossidae, low-duty-cycle bats. Pinnae are central to sound reception in general, and in some species large pinnae are thought to amplify the faint, low-frequency sounds emanating from moving prey (Guppy and Coles, 1988a; e.g. Megaderma lyra, Fiedler, 1979; Antrozous pallidus, Bell, 1982; Macrotus californicus, Bell, 1985). But large pinnae are not always associated with the use of passive sound in hunting. Several plecotine vespertilionids have very large pinnae, notably species in the genera Plecotus, Idionycteris, Corynorhinus and Euderma. Some of these bats show flexible hunting and echolocation behaviour (e.g. Idionycteris phyllotis, Simmons and O'Farrell, 1977; Plecotus auritus, Anderson and Racey, 1991), while others, such as Euderma maculatum, search for, detect and pursue airborne targets in a more conventional insectivorous bat fashion (Woodsworth et al. 1981; Fenton, 1990). Euderma maculatum, 
however, is distinctive for its use of sonar signals of low frequency $(6-12 \mathrm{kHz}$; Leonard and Fenton, 1984).

The purpose of this study was to examine the effects of pinnae on sound reception in bats. We made a threefold comparison: (1) echolocating with non-echolocating species; (2) echolocating species using different call designs; and (3) echolocating species that also rely on prey-generated sounds to locate their food. This comparison permitted us to test the hypothesis that the ear morphology and the passive properties of bat pinnae mirror the acoustic behaviour of bat species. We expected to find a close correspondence between the degree of frequency specialization of sonar signals and the acoustic properties of the external ears. Furthermore, since interaural pressure difference becomes a cue for azimuthal sound localization at higher frequencies (Gourevitch, 1987), we also tested the hypothesis that the performance of bats in pure-tone lateralization experiments (Witzke, 1989) is partly a function of the passive acoustic properties of their pinnae, particularly of the interaural intensity differences.

Over a range of frequencies, we calculated three main variables. First, signal amplification contributed by the pinnae as the pinna-induced pressure gain by comparing specimens with and without pinnae. Second, the hearing directionality associated with the pinnae by the $-3 \mathrm{~dB}$ acceptance angle (Coles and Guppy, 1986). Third, the contributions of pinnae to lateralization of sounds, the binaural directionality or interaural intensity difference.

\section{Materials and methods}

\section{Data collection}

We measured alcohol-preserved specimens (from the collection of the Department of Mammology, Royal Ontario Museum, Toronto) and a few frozen specimens (University of Munich) of 47 bat species (1-3 individuals per species) from 13 families (Table 1). In a few species, results obtained from specimens using both methods of preservation were compared. Pinna length (tip to base) and pinna width (largest width of pinna, Fig. 1C) were measured for the right ear to the nearest $0.5 \mathrm{~mm}$. Alcohol-preserved specimens were kept in deionized water for at least $1 \mathrm{~h}$ before acoustic measurements to restore the water content and natural tension of the tissue. Measurements were performed in a small room (approximately $2 \mathrm{~m}^{3}$ ) lined with sound-absorbing material to decrease acoustic reflections. A calibration microphone (1/8inch Brüel and Kjaer, type 4138, protective grid removed) and a measuring amplifier (Brüel and Kjaer type 2610) were used to measure sound pressure levels. After opening the bulla from below, the microphone was fitted to a plastic cone (Schlegel, 1977a) whose tip was sealed with cyanoacrylate glue close to the position of the previously removed, right (also left in Cloeotis percivali and Lasiurus borealis) tympanic membrane (Jen and Chen, 1988, Coles et al. 1989). A sinewave generator (Hewlett Packard model 3594A sweeping local oscillator), a power amplifier (Krohn-Hite) and a custom-built electrostatic speaker $(2.5 \mathrm{~cm}$ diameter) were used for sound production. The speaker had a flat frequency response $( \pm 3 \mathrm{~dB})$ between 15 and $125 \mathrm{kHz}$, output was $15 \mathrm{~dB}$ weaker at $5 \mathrm{kHz}$ and a gradual drop of $20 \mathrm{~dB}$ occurred between 135 and $225 \mathrm{kHz}$. Standing waves in the microphone-cone assembly created 
Table 1. Species examined and characteristic findings

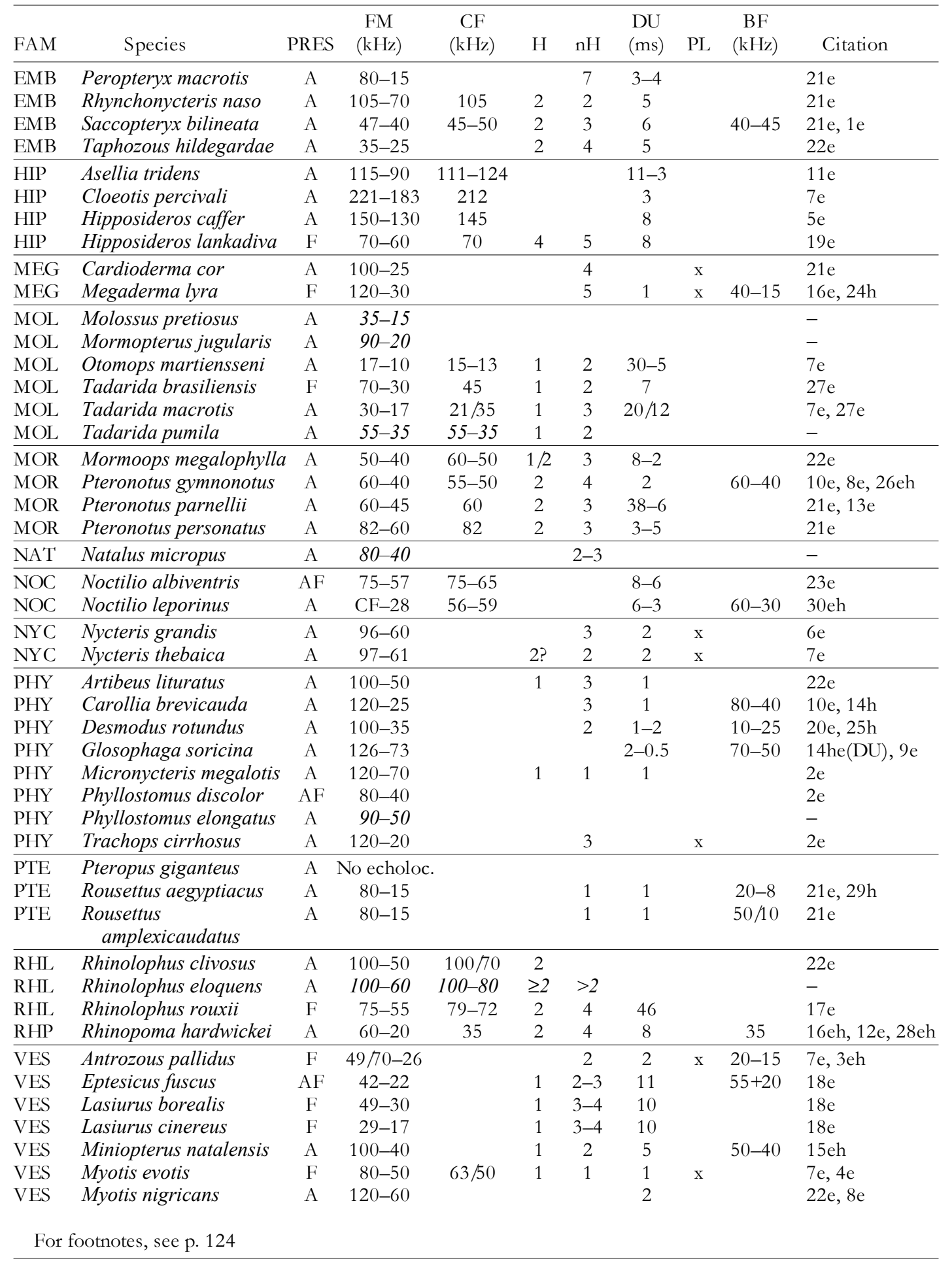


Table 1. Continued

\begin{tabular}{|c|c|c|c|c|}
\hline $\begin{array}{l}\mathrm{HT} \\
(\mathrm{mm})\end{array}$ & $\begin{array}{l}\text { WT } \\
(\mathrm{mm})\end{array}$ & HIID & PG & VAR \\
\hline 12.5 & 8.0 & $29 / 55$ & $12 / 25$ and $85-95$ & None \\
\hline 8.5 & 4.5 & $18 / 55,27 / 85$ & $11 / 25-35$ & Drop of $-3 \mathrm{~dB}$ angles at $45-55 \mathrm{kHz}$ \\
\hline 10.5 & 5.0 & $27 / 45-55$ & $<10 / 5-125$ & IFD steepest at $45-90 \mathrm{kHz}$ \\
\hline 17.0 & 12.0 & $35 / 45$ & $18 / 55$ & Decreased lat. perf. at $75-105 \mathrm{kHz}$ \\
\hline 15.5 & 12.5 & $35 / 115$ & $20 / 135$ & S teep IFD and peak HIID at CF \\
\hline 6.8 & 8.0 & $30 / 125,28 / 165$ & $20 / 165,10 / 205$ & High PG and steep IFD at 4th (?) harmonic \\
\hline 10.0 & 12.0 & $>25 / 25-125$ & $18 / 35$ & Steep IID at CF \\
\hline 26.0 & 21.0 & $>40 / 65-125$ & $30 / 45$ & Steepest IFD and drop in $-3 \mathrm{~dB}$ angle at CF \\
\hline 29.0 & 15.0 & $24 / 25$ and $95-105$ & $22 / 15,28 / 45$ & High PG at low frequencies \\
\hline 33.5 & 15.5 & $35 / 35$ & $19 / 15,21 / 55$ & Locally flatter IFD at $35 \mathrm{kHz}$ \\
\hline 10.0 & 6.0 & $>22 / 15-55$ & $12 / 25,10 / 55$ & None \\
\hline 10.5 & 10.5 & $>25 / 35-85$ & $12 / 25,15 / 85$ & None \\
\hline 33.0 & 18.0 & $35 / 45$ & $12 / 5$ and 65 & Local $-3 \mathrm{~dB}$ angle drop at $15 \mathrm{kHz}$ \\
\hline 15.0 & 10.0 & $25 / 45$ & $10 / 15-25,12 / 65-75$ & IFD steepest and highest at $35-55 \mathrm{kHz}$ \\
\hline 27.5 & 8.5 & $27 / 25$ & $15 / 55$ & IFD steepest and second peak at $25-45 \mathrm{kHz}$ \\
\hline 11.5 & 10.0 & $>25 / 45-85$ & $13 / 15, \leq 10 / 25-125$ & $-3 \mathrm{~dB}$ angles high and IFD flat at $75-85 \mathrm{kHz}$ \\
\hline 11.5 & 9.5 & $30 / 45-55$ & $20 / 15$ & High PG at low frequency \\
\hline 14.5 & 7.5 & $31 / 105$ & $12 / 25,15 / 105$ & IFD steepest at second harmonic of $\mathrm{CF}(45-55 \mathrm{kHz})$ \\
\hline 17.0 & 8.0 & $32 / 65,40 / 115$ & $16 / 95$ & IFD steepest at second harmonic of $\mathrm{CF}(45-75 \mathrm{kHz})$ \\
\hline 11.5 & 7.0 & $32 / 65$ & $<10 / 5-125$ & None \\
\hline 11.5 & 10.5 & $25 / 45,32 / 85$ & $13 / 25$ & None \\
\hline 22.0 & 9.5 & $>35 / 65-75$ & $10 / 55-75,15 / 85-95$ & IFD: high inclination and local maxima at $70 \mathrm{kHz}$ \\
\hline 16.5 & 7.0 & $30 / 85$ & $12 / 15$ & None \\
\hline 24.5 & 14.0 & $>22 / 15-55,31 / 115$ & $15 / 15$ & Decreased lat. perf. at $60-80 \mathrm{kHz}$ \\
\hline 23.0 & 14.5 & $20 / 25$ & $15 / 15$ & Decreased lat. perf. around $95 \mathrm{kHz}$ \\
\hline 15.5 & 10.5 & $33 / 25,32 / 85$ & $10 / 85$ & Decreased lat. perf. at $55-65 \mathrm{kHz}$ \\
\hline 14.2 & 9.5 & $\approx 35 / 65-85$ & $>10 / 65-75$ & High PG and HIID at BF \\
\hline 15.0 & 7.5 & $35 / 95$ & $30 / 35$ & Local minima of $-3 \mathrm{~dB}$ angles at $25-35 \mathrm{kHz}$ \\
\hline 11.2 & 7.2 & $>25 / 45-75$ & $10 / 15-25,5 / 65$ & No specialities \\
\hline 20.0 & 10.0 & $>20 / 25-75$ & $11 / 25$ and $95-115$ & None \\
\hline 15.5 & 11.0 & $>25 / 45-65$ & $10 / 45$ & None \\
\hline 19.5 & 14.5 & $>25 / 25-125$ & $12 / 15$ & None \\
\hline 26.0 & 17.0 & $27 / 5$ & $<10 / 5-105,12 / 115$ & IFD steep at $5-85 \mathrm{kHz}$ \\
\hline 31.0 & 18.0 & $>25 / 15-125$ & $15 / 45$ & None \\
\hline 18.5 & 11.0 & $>30 / 55$ & $<10 / 5-125$ & Low PG \\
\hline 14.0 & 10.0 & $20 / 35-55$ & $<10 / 5-125$ & Low PG \\
\hline 17.0 & 13.0 & $>28 / 75-105$ & $>10 / 25-95$ & IFD steepest and peak at $95 \mathrm{kHz}$ \\
\hline 19.5 & 18.5 & $35 / 35,>20 / 25-125$ & $13 / 15,15 / 105$ & IFD steepest at $45-65 \mathrm{kHz}$ \\
\hline 18.5 & 13.5 & $34 / 75$ & $24 / 85$ & IFD steepest and highest at $70-80 \mathrm{kHz}$ \\
\hline 17.5 & 11.5 & $>25 / 25-125,30 / 35$ & $12 / 25,20 / 65$ & Drop of $-3 \mathrm{~dB}$ angles at $35 \mathrm{kHz}$ \\
\hline 25.5 & 13.5 & $28 / 25$ & $15 / 15,25 / 55$ & High PG at low and at call frequency \\
\hline 13.0 & 9.5 & $35 / 45$ & $16 / 65$ & Steepest IFD and peak HIID at $25-65 \mathrm{kHz}$ \\
\hline 9.0 & 6.0 & $>10 / 35-110$ & $12 / 20$ and 80 & $-3 \mathrm{~dB}$ angles drop at $35-40 \mathrm{kHz}$ \\
\hline 12.5 & 11.5 & $>25 / 15-125$ & $10 / 45$ & None \\
\hline 9.0 & 7.0 & $>20 / 45-125$ & $12 / 15$ & None \\
\hline 18.5 & 8.5 & $40 / 45$ & $12 / 15,17 / 55$ & $-3 \mathrm{~dB}$ angles drop at $65 \mathrm{kHz}$ \\
\hline 9.5 & 7.5 & $32 / 65$ & $5-10 / 15-125$ & None \\
\hline
\end{tabular}




\section{Table 1. Footnotes.}

FAM, family: EMB, Emballonuridae; HIP, Hipposideridae; MEG, Megadermatidae; MOL, Molossidae; MOR, Mormoopidae; NAT, Natalidae; NOC, Noctilionidae; NYC, Nycteridae; PHY, Phyllostomidae; PTE, Pteropodidae; RHL, Rhinolophidae; RHP, Rhinopomatidae; VES, Vespertilionidae.

PRES, method of preservation: F, frozen; A, alcohol-preserved specimen measured. FM: dominant spectral range of frequency-modulated echolocation call component.

CF: dominant spectral range of narrow-band or constant-frequency echolocation call component.

$\mathrm{H}$ : number of the harmonic with main energy (fundamental=first harmonic).

$\mathrm{nH}$ : total number of harmonics.

DU: signal duration.

PL: $\mathrm{x}$ if known to locate prey by passive listening to prey-generated noises.

$\mathrm{BF}$ : best frequency, the frequency of best hearing.

Citation: source of echolocation (e) and hearing (h) data. 1, Barclay (1983); 2, Belwood (1988);

3, Brown and Grinnell (1980); 4, Faure et al. (1990); 5, Fenton (1986); 6, Fenton (1988); 7, Fenton and Bell (1981); 8, Fullard and Belwood (1988); 9, Griffin and Novick (1955); 10, Grinnell (1970); 11, Gustafson and Schnitzler (1979); 12, Habersetzer (1981); 13, Henson et al. (1987); 14, Howell (1974); 15, Jen and Suthers (1982); 16, Neuweiler et al. (1984); 17, Neuweiler (1984); 18, Obrist (1989); 19, Peters (1987); 20, Pye (1980a); 21, Pye (1980b); 22, J. D. Pye, personal communication; 23, Roverud and Grinnell (1985); 24, Schmidt et al. (1984); 25, Schmidt et al. (1991); 26, Simmons et al. (1975); 27, Simmons et al. (1978); 28, Simmons et al. (1984); 29, Suthers and Summers (1980); 30, Wenstrup (1984).

HT: pinna height.

WT: pinna width.

HIID: $(x / y)$ highest interaural intensity difference $(x$ in $\mathrm{dB})$ located at frequency $(y$ in $\mathrm{kHz})$.

PG, $(x / y)$ highest pinna gain $(x$ in $\mathrm{dB})$ located at frequency $(y$ in $\mathrm{kHz})$.

VAR: various conspicuous specialities; PG, pinna gain; IFD, IID frequency display; HIID, highest interaural intensity difference; $\mathrm{BF}$, frequency of best hearing.

Values given in italics are proposed characteristics, suggested by our results.

prominent fluctuations of the microphone sensitivity $( \pm 10 \mathrm{~dB})$ over the frequency range used, precluding comparisons of absolute sound pressure levels between frequencies. Mounted on a freely movable arm, the speaker could be remotely positioned on a virtual sphere of $15 \mathrm{~cm}$ radius, centred at the position of the tympanic membrane (servo mechanism: Schlegel et al. 1988; Poussin and Schlegel, 1984). The frontal position of the bat (the assumed sonar direction; Fig. $1 \mathrm{~A}$ ) was aligned visually to $0^{\circ}$ elevation and $0^{\circ}$ azimuth. In Antrozous pallidus, Eptesicus fuscus, Megaderma lyra, Nycteris thebaica and

Fig. 1. Data sampling. (A) Representation of the bending of the sampled spherical field to a plane. The direction of the emission of the sonar signal is defined as sonar horizon ( $\mathrm{SH}$ ). $(B-G)$ Sound pressure transformations of the right ear of three bat species with a sketch of their heads. Lasiurus borealis at $35 \mathrm{kHz}$ with pinna present (B) and pinna absent (E). Hipposideros caffer at $75 \mathrm{kHz}$ with pinna present (C) and pinna absent (F). Nycteris grandis at $35 \mathrm{kHz}$ with pinna present $(\mathrm{D})$ and pinna absent $(\mathrm{G})$. Sound pressure is plotted in $\mathrm{dB}$ re the peak (dot). Contours of $-1 \mathrm{~dB},-2 \mathrm{~dB}$ and $-3 \mathrm{~dB}$ are plotted and kept white. The largest angular width of this white area defines the $-3 \mathrm{~dB}$ acceptance angle in azimuth, the largest height the $-3 \mathrm{~dB}$ acceptance angle in elevation (compare Figs 5 and 11). A contour interval of $6 \mathrm{~dB}$ was then used to distinguish between successively lower contours (increasing darkness). The positions of measurements of largest height (HT) and width (WT) of the pinnae (compare Table 1 and Fig. 7) are indicated in the sketch of the head of Hipposideros caffer. 

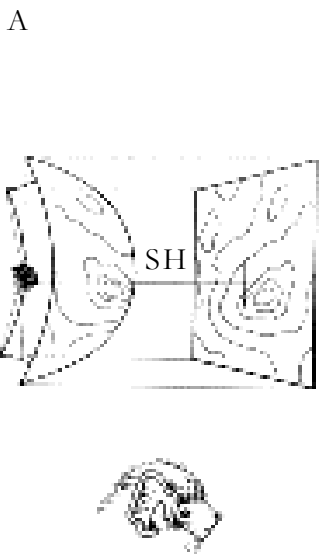

Lasiurus borealis

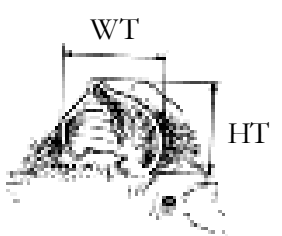

Hipposideros caffer

Nycteris grandis
$1 \mathrm{~cm}$

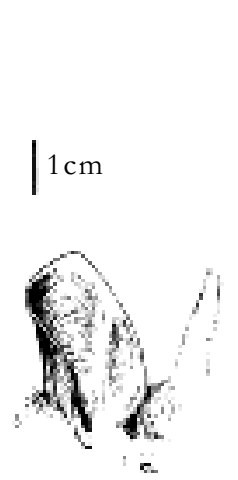

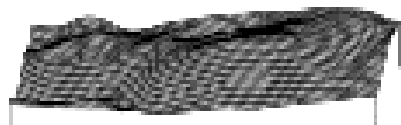

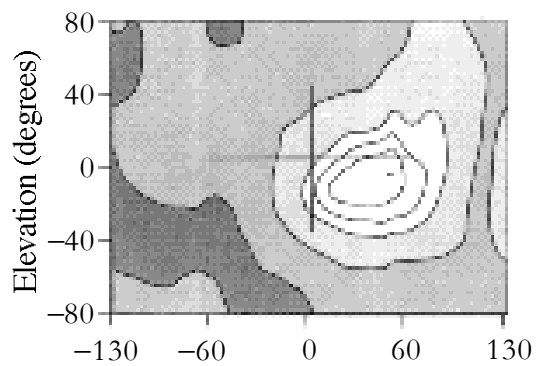

$35 \mathrm{kHz}$
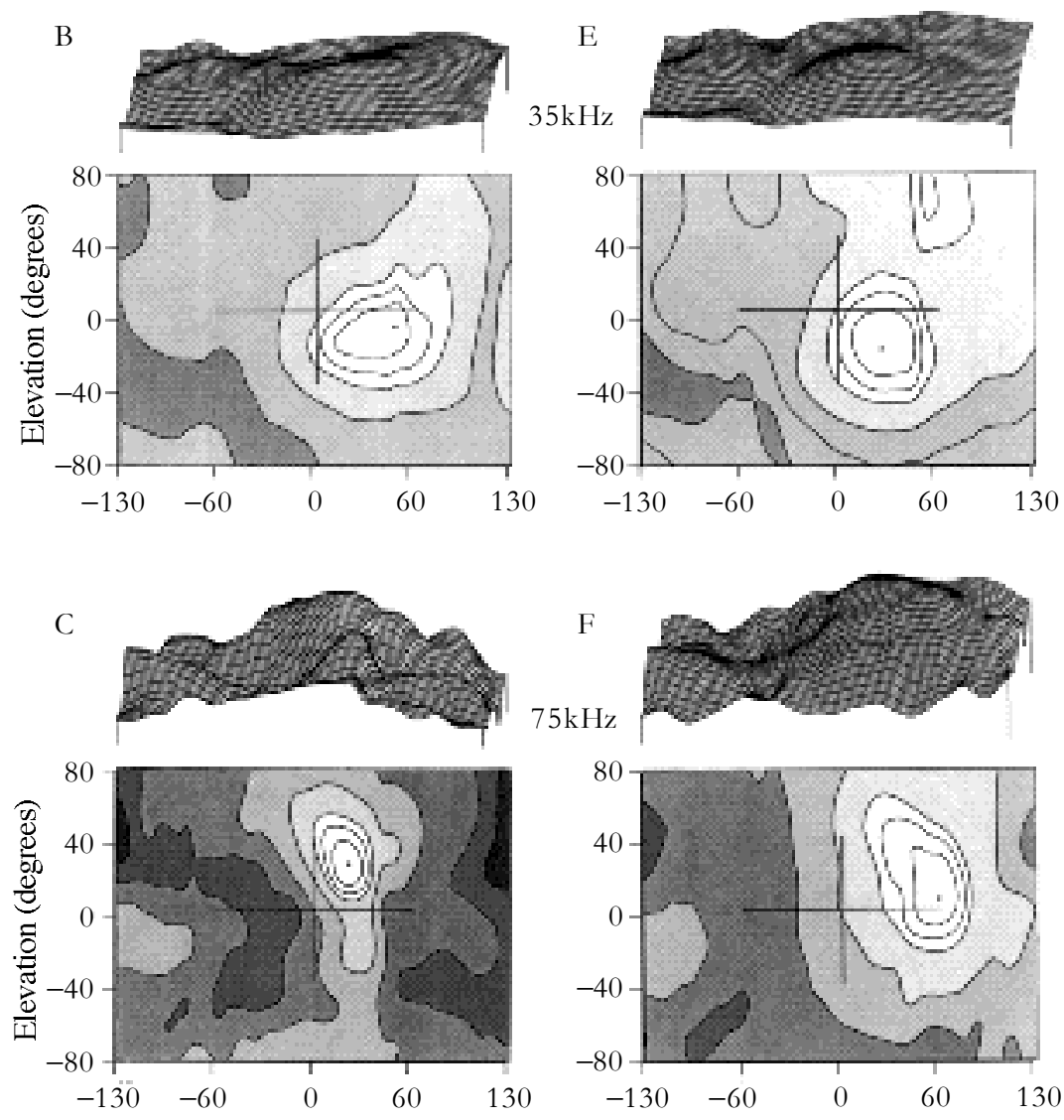
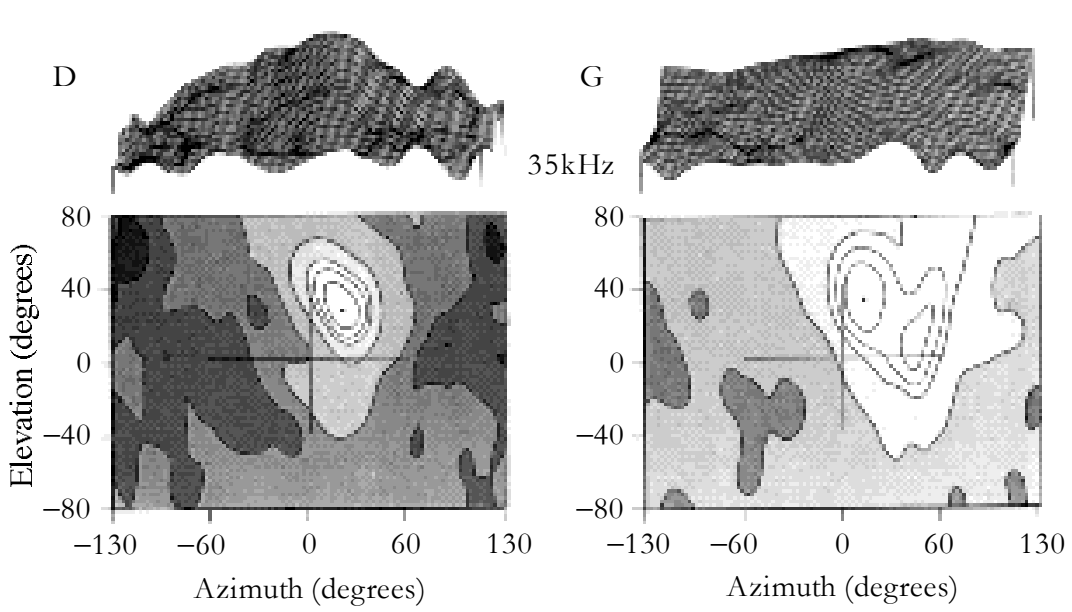

Fig. 1 
Rhinolophus rouxi, flight photographs were used as a reference for the head orientation in the set-up. In species with nose leaves, these structures were set perpendicular to the horizontal plane, defined as the sonar horizon (see Results and Coles et al. 1989). A photograph was taken of every preparation for later comparison with collected data (e.g. position of acoustic axis, see below). The automated sampling scanned an area of $-130^{\circ}$ to $+130^{\circ}$ azimuth from the sagittal plane in steps of $2.00^{\circ}\left( \pm 0.25^{\circ}\right)$ and of $-80^{\circ}$ to $+80^{\circ}$ elevation from the sonar horizon in steps of $6.15^{\circ}\left( \pm 0.75^{\circ}\right)$. The restriction of the scanning sphere to $260^{\circ}$ azimuth times $160^{\circ}$ elevation resulted from the mechanical arrangement. Continuous pure tones from 5 to $125 \mathrm{kHz}$ were used in $10 \mathrm{kHz}$ steps $(5-120 \mathrm{kHz}$ in $5 \mathrm{kHz}$ steps in L. borealis) with sound pressure levels of 80-120dB SPL as test signals. An extended frequency range was tested with the $10 \mathrm{kHz}$ step width in three Hipposideridae (Asellia tridens: 5-155kHz, Cloeotis percivali: 5-225kHz, Hipposideros caffer: $5-205 \mathrm{kHz}$ ). To prevent measurements of spurious harmonics or noise, the signal registered by the microphone and amplified by the measuring amplifier was bandpassfiltered with $3100 \mathrm{~Hz}$ bandwidth, centred at the testing frequency (Hewlett Packard model $3590 \mathrm{~A}$ wave analyzer). The sound pressure was measured as voltage re $20 \mu \mathrm{Pa}$ with a 12 bit A/D-converter board (Data Translation DT 2801A) installed in a microcomputer (Compaq Portable III). The same board also controlled the signal frequency (accurate to $\pm 1 \%)$ and the servo mechanism, which executed the speaker movements. The automated measurement of 13 frequencies was accomplished in approximately $40 \mathrm{~min}$, the pinna of the measured ear was then removed and the same series of measurements was repeated. An adapted version of ASYST (ASYST Software Technologies) was used for data collection, analysis and display.

\section{Data analysis}

The sampled sound pressure values were stored in an array containing $26 \times 130$ data points. Further calculations were performed with this array. The position of the peak indicated the acoustic axis of the ear at a given frequency. By subtracting the intensity value measured at this position in the pinna-deprived preparation from the value sampled with the intact ear, we determined the pinna-induced pressure gain. As a measure of the directionality of the sound pressure transformation, the angular width (azimuth) and height (elevation) of a contour line $3 \mathrm{~dB}$ below the peak were calculated; we have called this the $-3 \mathrm{~dB}$ acceptance angle (Coles and Guppy, 1986; see also Fig. 1).

We measured the characteristics of only one ear, assuming that both ears are symmetrical relative to the mid-sagittal plane. By adding the original data array to a copy of itself, mirrorred along the vertical central axis, we created a display of the total binaural directionality of hearing (Fig. 2A-D). Subtracting the mirrorred field from the original one creates a representation of the interaural intensity difference (IID; Fig. 2E-H), in some

Fig. 2. Directionality of the binaural hearing field (A-D) and binaural sound pressure difference $(\mathrm{E}-\mathrm{H})$. Total binaural directionality of the sound pressure transformation of the ears of Lasiurus borealis at $10 \mathrm{kHz}$ (A) $20 \mathrm{kHz}$ (B), $40 \mathrm{kHz}$ (C) and $80 \mathrm{kHz}$ (D), calculated by adding the monaural input to a mirrored copy of itself. $(\mathrm{E}-\mathrm{H})$ Interaural intensity difference (IID) calculated by subtracting the mirrored copy from the monaural original (right ear measured) at the same frequencies in L. borealis. 
D
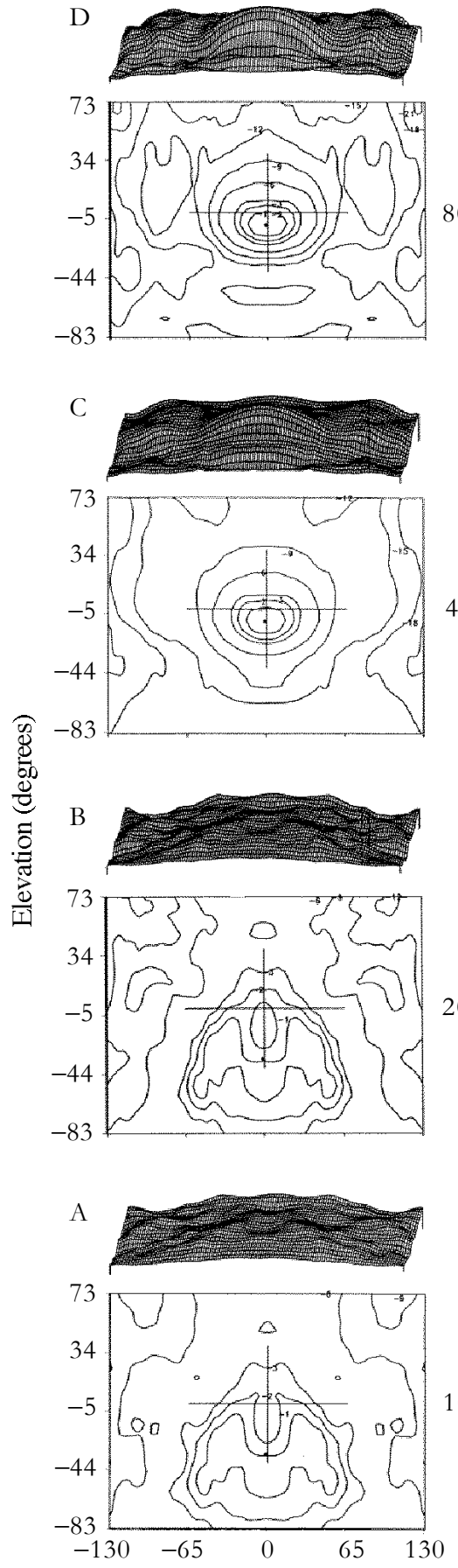

Azimuth (degrees)

Fig. 2
$\mathrm{H}$

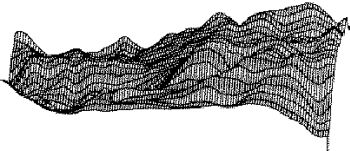

$80 \mathrm{kHz}$

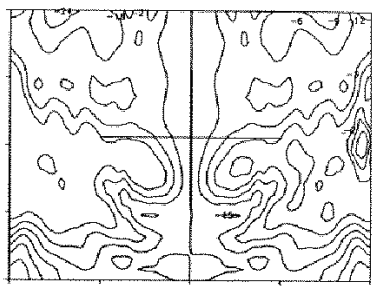

G
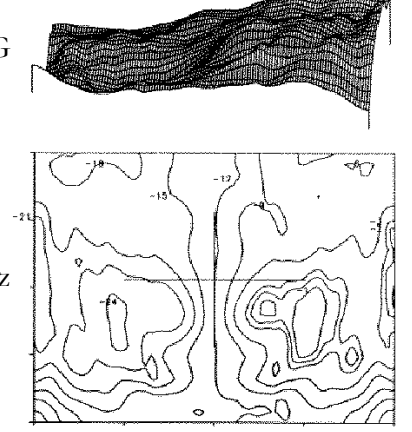

F
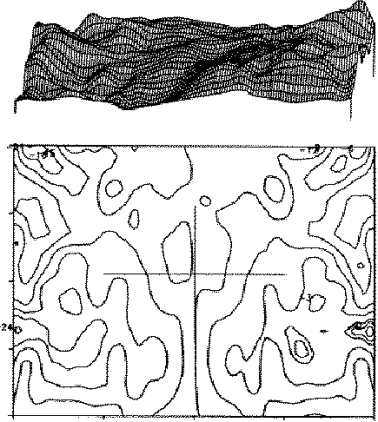

E
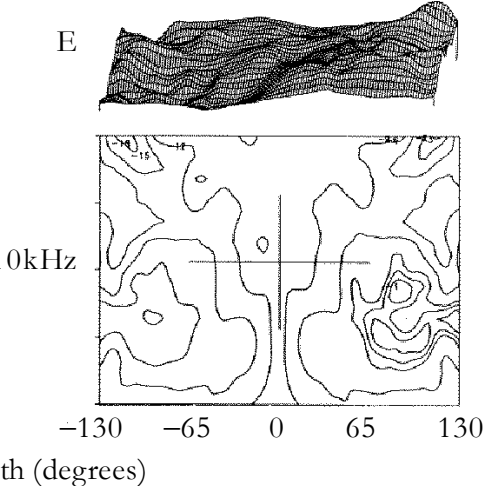


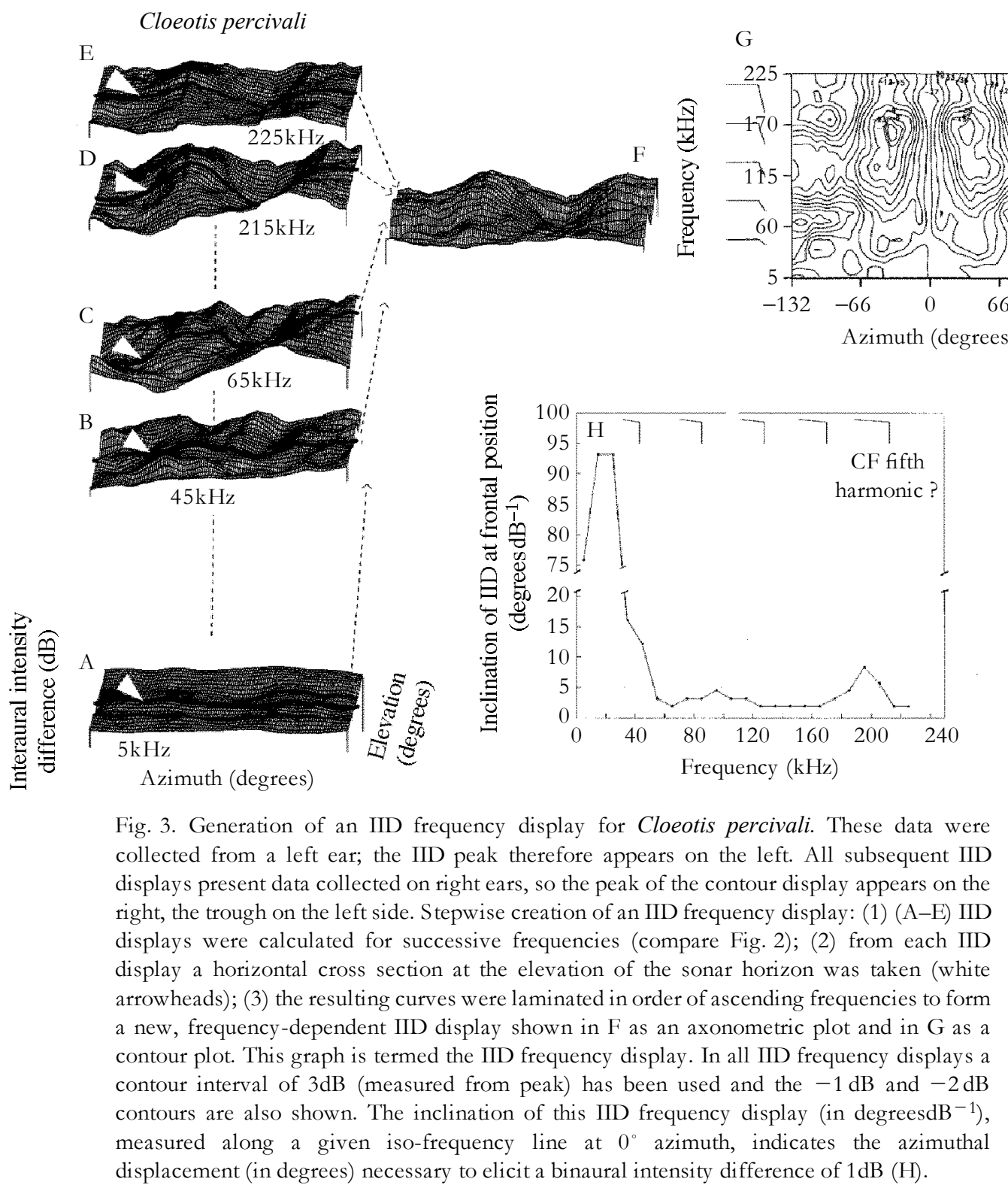

publications referred to as interaural level difference (ILD). The peak value in this derived array indicates the highest interaural intensity difference (HIID) for a given frequency. A horizontal cross section of this IID array at the sonar horizon was extracted for consecutive frequencies (open arrowheads in Fig. 3A-E) and laminated to a new array, termed the IID frequency display, now coding IID at the sonar horizon ( $z$-axis) as a function of azimuth $(x$-axis) and frequency ( $y$-axis) (Fig. 3F, axonometric plot; Fig. 3G, contour line plot). The azimuthal inclination of the first IID data field (in degrees $\mathrm{dB}^{-1}$ ) records the intensity 
change occurring between the two ears for a given change in lateral position at any given elevation. We therefore calculated, in the derived IID frequency display, the inclination at the sagittal plane $\left(0^{\circ}\right.$ azimuth; Fig. $\left.3 \mathrm{H}\right)$, which in turn codes the frequency-dependent IID change available to the bat for lateralization of a pure-tone sound source at the frontal position. The IID frequency displays and the $-3 \mathrm{~dB}$ acceptance angles were of highest value for the comparison of the data with the animal's behaviour.

\section{Results}

\section{General features concerning all species}

A graphic visualization (Fig. 1A) of the sound pressure arriving at the tympanic membrane helps us to understand the animal's perception of its acoustic surroundings and the three features we assessed. Sound pressure distribution (directionality) is illustrated in Fig. 1 as an axonometric pseudo-three-dimensional plot and as a contour plot (top and bottom, respectively, in Fig. 1B-G). A comparison of pinna-present (Fig. 1B-D) and pinna-absent (Fig. 1E-G) presentations demonstrates the pinna-induced increase of directionality and shows the effect of ear size (compare Fig. 1B and Fig. 1D). The pinnae work like magnifying glasses so moving them means changing the position of the acoustic axis, the 'focus' of the magnifying glass. In Fig. 1, directionality is indicated by the angular diameter (in degrees) of a slice through the 'acoustic mountain' $3 \mathrm{~dB}$ under the peak $(-3 \mathrm{~dB}$ acceptance angle; Fig. 1B-G, contour plots). The steepness of the mountain shows the 'sharpness' of the pinna as an acoustic magnifying glass.

The contributions of the pinnae to binaural directionality are shown for Lasiurus borealis in Fig. 2. Here, adding the inputs of both ears creates the symmetrical sensitivity pattern of the two pinnae (Fig. 2A-D). By subtracting the input to the left ear from the input to the right ear, we illustrate binaural directionality expressed as the sound pressure difference (IID; Fig. 2E-H; see also the data analysis for the calculation of the left ear input). The IID is the only intensity cue available to a bat for differentiating left from right. Steeper displays at the frontal vertical centre line show larger sound pressure differences between the two ears when a sound source moves laterally. A steep IID at the frontal position means potentially finer resolution of lateralization. Ear characteristics and IIDs change with frequency (Fig. 2A-D and E-H measured at $10-80 \mathrm{kHz}$ ). To compare the frequency-dependent effect on the frontal IID inclination, we plotted this inclination (measured at $0^{\circ}$ elevation, $0^{\circ}$ azimuth) as a function of frequency (e.g. Figs 3, 6, 9, 10 and 14). These graphs predict the frequency-dependent lateralization performance for sound sources directly in front of the bat (see Fig. 14).

None of the measured variables alone accounted for the acoustic behaviour of the bats. In some species, pinna gain reached maximum values in behaviourally relevant frequency regions, while in others this was true of directionality or of the binaural effects (IID). We combined information for pinna gain, $-3 \mathrm{~dB}$ acceptance angles and IID to investigate the relationships between pinnae and acoustic orientation. We found some general trends in all species analyzed.

At higher frequencies, the position of the acoustic axis moved towards higher elevations and the sagittal midline (Fig. 4), eventually reaching a relatively stable plateau 


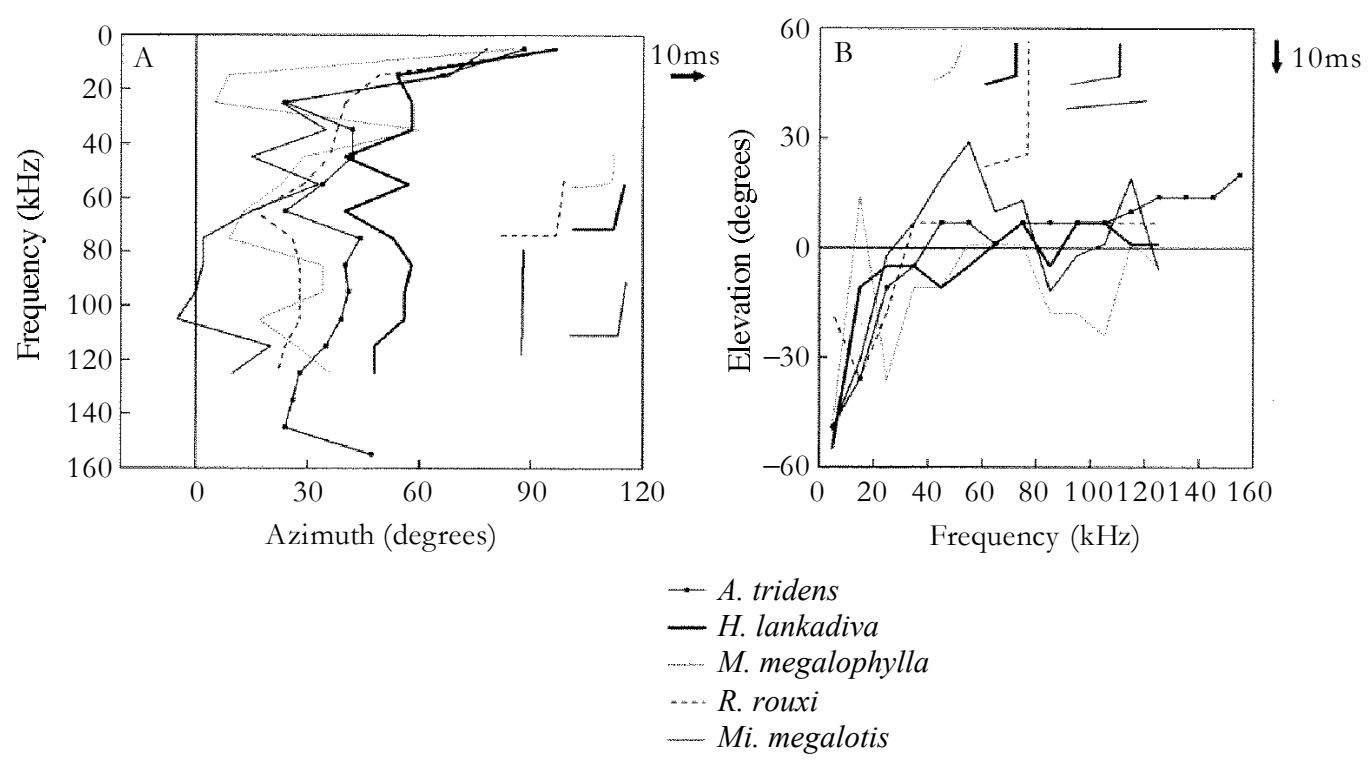

Fig. 4. The position of the acoustic axis in azimuth (A) and elevation (B) determined in five bat species. With increasing frequency the axis moves towards the frontal direction in azimuth and elevation.

above approximately $60 \mathrm{kHz}$. Species with small pinnae (e.g. Myotis nigricans, Cloeotis percivali) did not show a clearly defined peak at low frequencies $(<15 \mathrm{kHz})$. In some Hipposideridae and Rhinolophidae, the elevation of the acoustic axis reached a plateau at higher frequencies and in molossids the vertical position changed less drastically than in other families. In most species emitting downward frequency-modulated calls (FM), the axis crossed $0^{\circ}$ elevation in the spectral range of the echolocation calls, defining a sonar horizon (Coles et al. 1989). When we found a clear deviation from this pattern, the elevation of the horizontal cross sections for the calculation of the IID frequency field was adjusted to achieve an IID frequency display derived from elevations of comparable acoustical importance (the sonar horizon).

Pinnae showed increasing directionality with increasing frequency (Fig. 2A-C), affecting the extent of interaural intensity differences (Fig. 2D-E). The $-3 \mathrm{~dB}$ acceptance angle decreased linearly with increasing wavelength (decreasing exponentially with increasing frequency, Fig. 5). The elevational height of the $-3 \mathrm{~dB}$ acceptance angle reached about $40^{\circ}$ above $60 \mathrm{kHz}$ and reached a minimum of $20^{\circ}$ above $100 \mathrm{kHz}$. The angle tended to be smaller in elevation mainly because the pinna dimensions are asymmetric. In general a $-3 \mathrm{~dB}$ acceptance angle width of $\leqslant 30^{\circ}$ was reached above $80 \mathrm{kHz}$. The removal of the pinna always reduced directionality (increased $-3 \mathrm{~dB}$ acceptance angle); this was usually accompanied by a decrease of the total dynamic range recorded over the sampled area (compare Fig. 1B-D with Fig. 1E-G). The direction of the acoustic axis shifted unpredictably after removal of the pinna. 

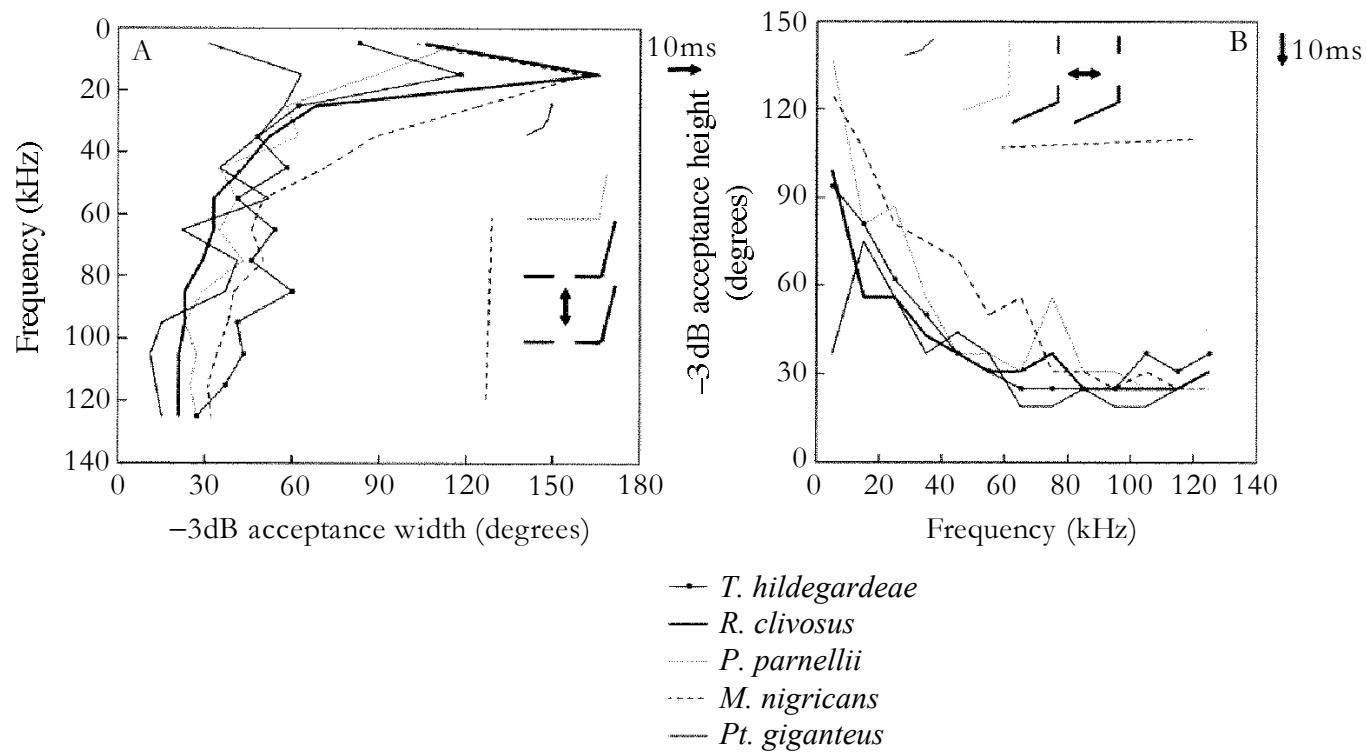

Fig. 5. $-3 \mathrm{~dB}$ acceptance angles in azimuth (A) and elevation (B) in five bat species (see also Fig. 1). Angles decrease with increasing frequency. Because of oblong pinna shapes, azimuthal angles reach smaller values than elevational ones.

\section{Effects of preservation and sample size}

The alcohol-preserved and frozen specimens of the frugivorous Phyllostomus discolor reached maximum IID $(25-30 \mathrm{~dB})$ in the lower range of their echolocation calls $(40 \mathrm{kHz})$. The frozen specimen, however, showed a more regular rise of the IID with frequency and azimuth than the alcohol-preserved specimen. As in Phyllostomus discolor, the $-3 \mathrm{~dB}$ acceptance angles were the same in a frozen and an alcohol-preserved specimen of Noctilio albiventris (see Fig. 11A,B). The $-3 \mathrm{~dB}$ acceptance angles were the same for three different specimens of Lasiurus borealis.

\section{Echolocating and non-echolocating bats}

There were no striking differences between the pinnae of echolocating Rousettus aegyptiacus and $R$. amplexicaudatus and the non-echolocating Pteropus giganteus. Pteropus giganteus had the largest ears and showed the largest pinna gain compared with the two echolocators (see Table 1). The pinnae of all three species showed moderate directionality and binaural directionality was similar.

The binaural frequency-dependent directionality display (IID frequency display), however, was irregular in $R$. amplexicaudatus, while in $P$. giganteus it showed a relatively steady increase of IID with increasing azimuth and increasing frequency (Fig. 6A). In R. aegyptiacus, IID increased with frequency but decreased for azimuths above $60^{\circ}$ (Fig. 6B). In $P$. giganteus at $0^{\circ}$ azimuth, the IID frequency display showed a relatively stable slope of 3.3 degrees $\mathrm{dB}^{-1}$ over the whole frequency range. This inclination reached 1.9 degrees $\mathrm{dB}^{-1}$ above $25 \mathrm{kHz}$ in $R$. aegyptiacus (Fig. 6C). 
Pteropus giganteus

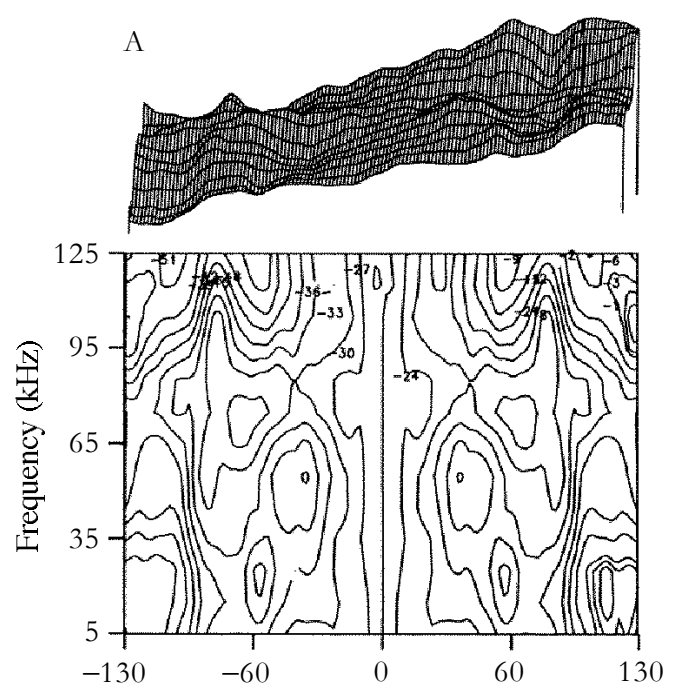

Rousettus aegyptiacus

B

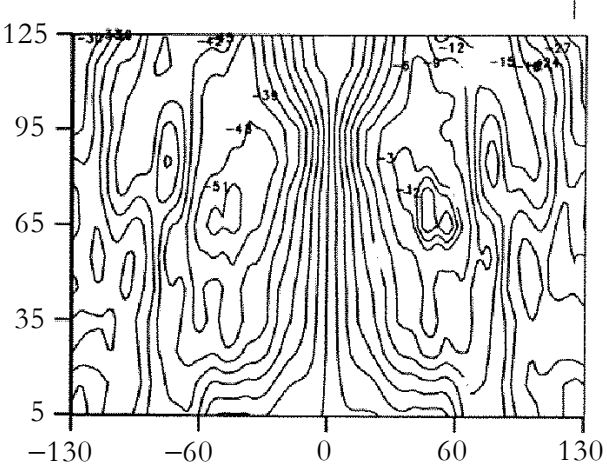

Azimuth (degrees)

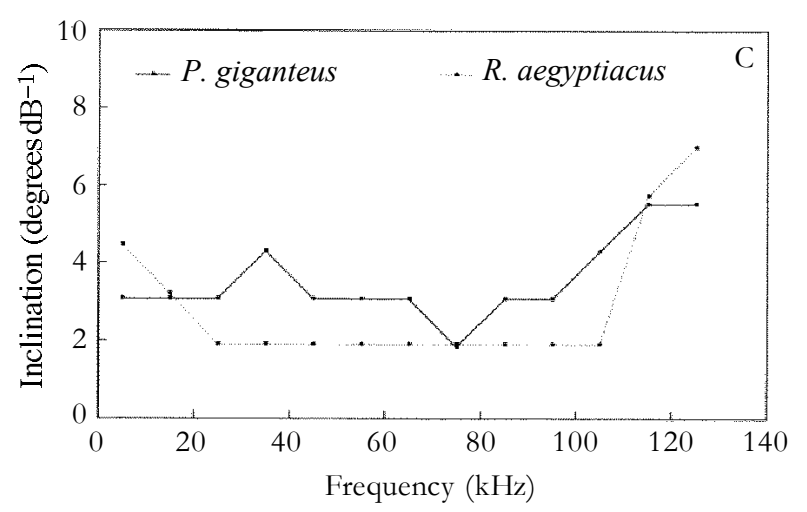

Fig. 6. IID frequency display for two megachiropteran bats, Pteropus giganteus (A) and Rousettus aegyptiacus (B). (C) Inclination of the IID frequency display at the frontal position in the same species. For further explanation, see Fig. 3.

\section{Low-duty-cycle broad-band echolocating bats}

In most bats using FM or multiharmonic broad-band search-phase signals, the correlation between ear dimensions and main echolocation call frequency, the frequency containing most energy in the power spectrum of the call (Fig. 7A,B), was not significant. Phyllostomids, for example, showed no consistently prominent feature in their ear characteristics, whether they fed on blood (Desmodus rotundus), nectar, pollen and insects (Glossophaga soricina), fruit (Phyllostomus elongatus) or insects (Micronycteris 


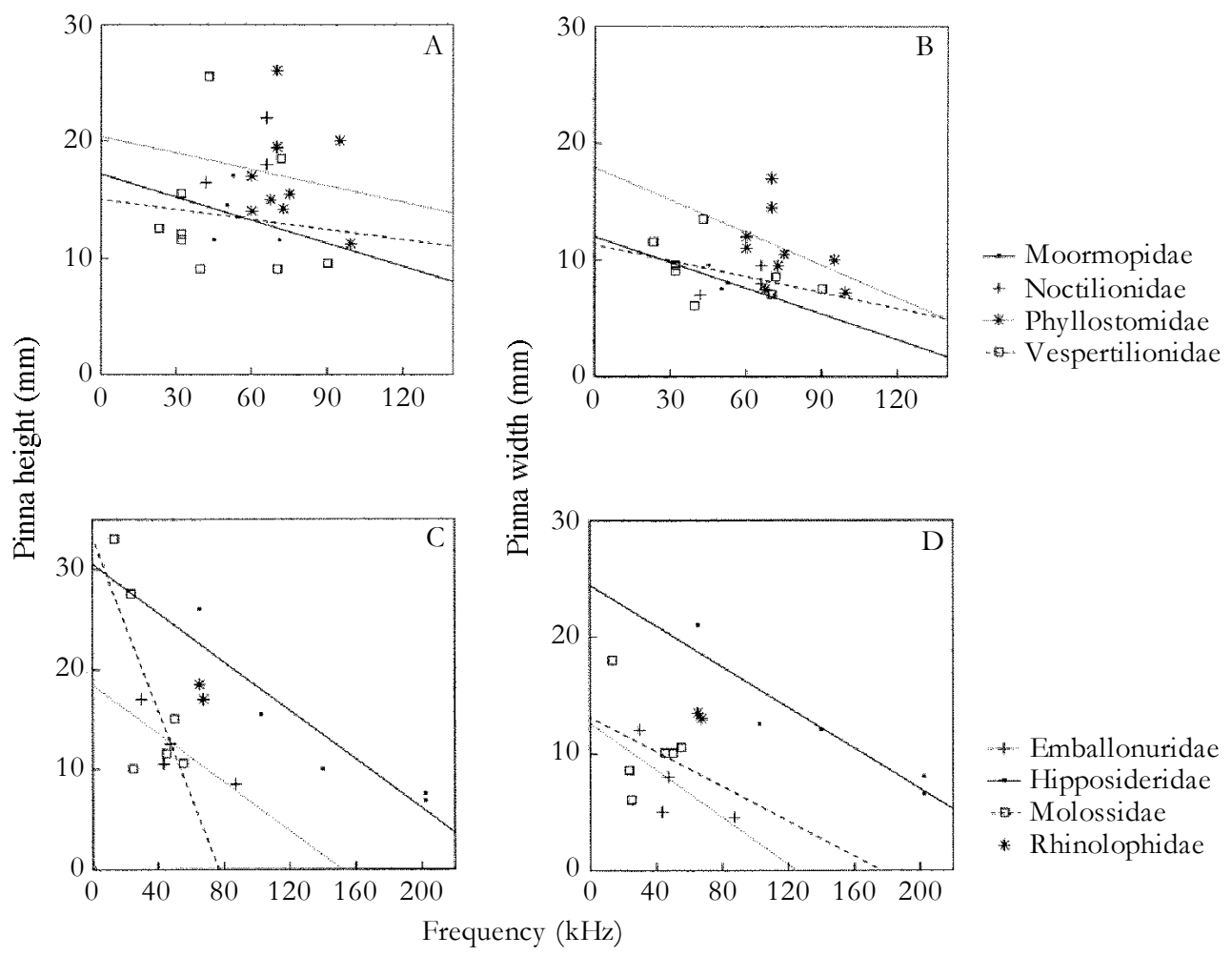

Fig. 7. Echolocation call frequencies and ear dimensions. Pearson's rank correlation of predominant echolocation call frequency (see Table 1: centre frequency of sweep range in FM bats, mean of CF frequencies in other bats) and pinna dimensions (see Fig. 1) in eight Microchiropteran families. Pinna height and frequency of main call energy are not correlated in Mormoopidae $(r=0.28, P=0.72)$, Phyllostomidae $(r=0.15, P=0.70)$, Vespertilionidae $(r=0.12, P=0.75)(\mathrm{A})$, Emballonuridae $(r=0.82, P=0.17)$ and Molossidae $(r=0.74, P=0.09)$ but are correlated in Hipposideridae $(r=0.93, P=0.02)(\mathrm{C})$. Pinna width and main call energy are not correlated in Mormoopidae $(r=0.77, P=0.22)$, Phyllostomidae $(r=0.41, P=0.26)$, Vespertilionidae $(r=0.45, P=0.21)(\mathrm{B})$, Emballonuridae $(r=0.73, P=0.27)$ and Molossidae $(r=0.31, P=0.54)$ but are correlated in Hipposideridae $(r=0.94, P=0.02)$ (D). No correlation was calculated for Noctilionidae and Rhinolophidae for which only two species with known echolocation calls were measured.

megalotis). Binaural directionality at the sonar horizon in D. rotundus (Fig. 8A) showed no prominent peaks and shallow inclinations for frontal directions $\left(5-10\right.$ degrees $\left.\mathrm{dB}^{-1}\right)$. There were some variations on this theme since one species (the frugivorous Carollia brevicauda) had a high pinna gain (maximum $18 \mathrm{~dB})$ and high IID $(\leqslant 36 \mathrm{~dB})$ in the spectral range of best hearing $(40-80 \mathrm{kHz})$ reported for a related species (Carollia perspicillata; Howell, 1974). In the frontal direction in C. brevicauda, the binaural directionality showed a constant inclination of 1.9 degrees $\mathrm{dB}^{-1}$ between 35 and $105 \mathrm{kHz}$, unlike the situation in $D$. rotundus where local minima in both $-3 \mathrm{~dB}$ acceptance angles at $25-35 \mathrm{kHz}$ coincided with the highest pinna gain (30dB). Relatively large pinnae 

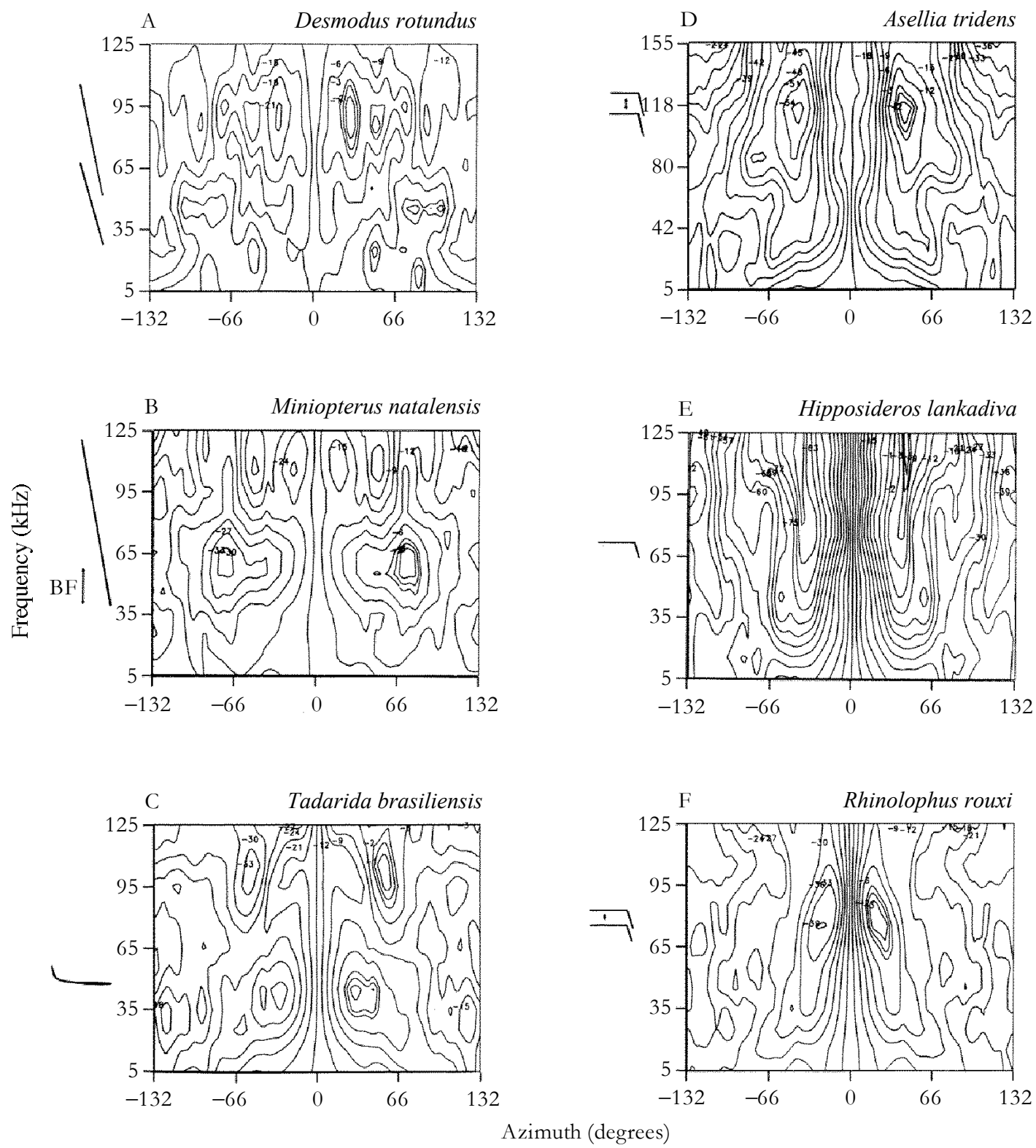

Fig. 8. IID frequency displays of Desmodus rotundus (A), Miniopterus natalensis (B), Tadarida brasiliensis (C), Asellia tridens (D), Hipposideros lankadiva (E) and Rhinolophus rouxi $(\mathrm{F})$. All data were collected from right ears; the peaks therefore have positive azimuths (see Fig. 3 for the creation of the IID frequency display). Clear structures with a unimodal peak appear in hipposiderids and rhinolophids (peaks at $118 \mathrm{kHz}, 55^{\circ}$ azimuth in $\mathrm{D}, 120 \mathrm{kHz}$, $55^{\circ}$ in $\mathrm{E}, 80 \mathrm{kHz}, 30^{\circ}$ in $\mathrm{F}$ ). A rather diffuse pattern appears in $\mathrm{A}$ and bimodal peaks with separating troughs can be seen in $\mathrm{B}$ (first peak at $55 \mathrm{kHz}, 70^{\circ}$ azimuth; second at $105 \mathrm{kHz}$, $55^{\circ}$ ) and $\mathrm{C}$ (first peak at $100 \mathrm{kHz}, 55^{\circ}$; second at $40 \mathrm{kHz}, 35^{\circ}$ ). Schematic sonagrams of species' echolocation calls are indicated to the left of the frequency scale. BF in B indicates the range of best hearing. 
meant that the frugivorous Artibeus lituratus had a maximum IID of $33 \mathrm{~dB}$ at $25 \mathrm{kHz}$. From this frequency to $45 \mathrm{kHz}$, the inclination of the IID frequency display at the frontal position showed a minimum of 1.9 degrees $\mathrm{dB}^{-1}$, then rose to $3.3 \mathrm{degrees} \mathrm{dB}^{-1}$ $(55-65 \mathrm{kHz})$ and dropped again to below 1.9 degrees $\mathrm{dB}^{-1}$ above $85 \mathrm{kHz}$.

In many Vespertilionidae, binaural directionality displays were obviously related to the frequencies dominating the echolocation calls, but the correlation between ear dimensions and main echolocation call frequency was not significant (Fig. 7). For example, in Eptesicus fuscus which uses relatively short broad-band FM calls, sweeping from approximately $40-20 \mathrm{kHz}$, to search for airborne prey, the display becomes steeper (up to 1.9 degrees $\left.\mathrm{dB}^{-1}\right)$ and the $\mathrm{HIID}(35 \mathrm{~dB})$ was located in this spectral area. Two other species using shorter, broad-band calls, Myotis nigricans and Miniopterus natalensis, have small ears which are fairly directional in the lower range of their echolocation calls (60 and $40 \mathrm{kHz}$ respectively). In this spectral range, both species had HIIDs of 25-30dB and the IID frequency display showed a steepness of 1.9 degrees $\mathrm{dB}^{-1}$. This inclination increased to $0.6 \mathrm{degreesdB}{ }^{-1}$ at $105 \mathrm{kHz}$ in $M$. nigricans, while it degraded above $75 \mathrm{kHz}$ in M. natalensis (Fig. 8B).

Most mormoopid bats use broad-band search-phase echolocation calls. The spectacular-looking ears of Mormoops megalophylla provided a pinna gain of $20 \mathrm{~dB}$ at $15 \mathrm{kHz}$, and the pinna characteristics corresponded to our knowledge of this species' biosonar calls. The HIID of $30 \mathrm{~dB}$ was reached between 45 and $55 \mathrm{kHz}$ and, after a drop of $10 \mathrm{~dB}$, the HIID rose again to $25 \mathrm{~dB}$ at $85 \mathrm{kHz}$. Both peaks and the peak and the inclination in the IID frequency display matched the two dominant harmonics in the biosonar signals (see Fig. 1A).

The $-3 \mathrm{~dB}$ acceptance angles measured did not seem to correspond to the echolocation behaviour of two species of Pteronotus. In P. personatus, the HIID (28-32dB) was located between 45 and $75 \mathrm{kHz}$, falling within the range of the $\mathrm{FM}$ portion of the dominant harmonic. In this region, the inclination of the IID frequency display at the frontal position remained relatively low (3.5degreesdB ${ }^{-1}$; see Fig. 12C). In P. gymnotus, however (Fig. 12B), these displays showed a marked increase in steepness (down to 0.6 degrees $\mathrm{dB}^{-1}$ at $50 \mathrm{kHz}$ ), but the absolute peaks were reached at higher frequencies.

If these generalizations apply to other bats, Natalus micropus (Natalidae) should use echolocation calls with two harmonics in the range $40-80 \mathrm{kHz}$. We base this prediction on three features of the pinnae: (1) the pinna gain amounts to $15 \mathrm{~dB}$ at $25 \mathrm{kHz}$ and $11 \mathrm{~dB}$ at $85 \mathrm{kHz}$; (2) the IID peaked at $45 \mathrm{kHz}(26 \mathrm{~dB})$ and $85 \mathrm{kHz}(32 \mathrm{~dB})$ and (3) binaural directionality data suggest maximum frontal inclination of 1.9 degreesdB ${ }^{-1}$ between 45 and $75 \mathrm{kHz}$.

\section{Low-duty-cycle narrow-band echolocating bats}

Species with search-phase echolocation calls dominated by narrow bandwidths (some species in the Rhinopomatidae, Emballonuridae, Mormoopidae, Noctilionidae and Vespertilionidae) showed a closer relationship between pinna dimensions and echolocation call characteristics than did broad-band species. Species with search-phase echolocation calls dominated by higher frequencies tended to have smaller ears, 


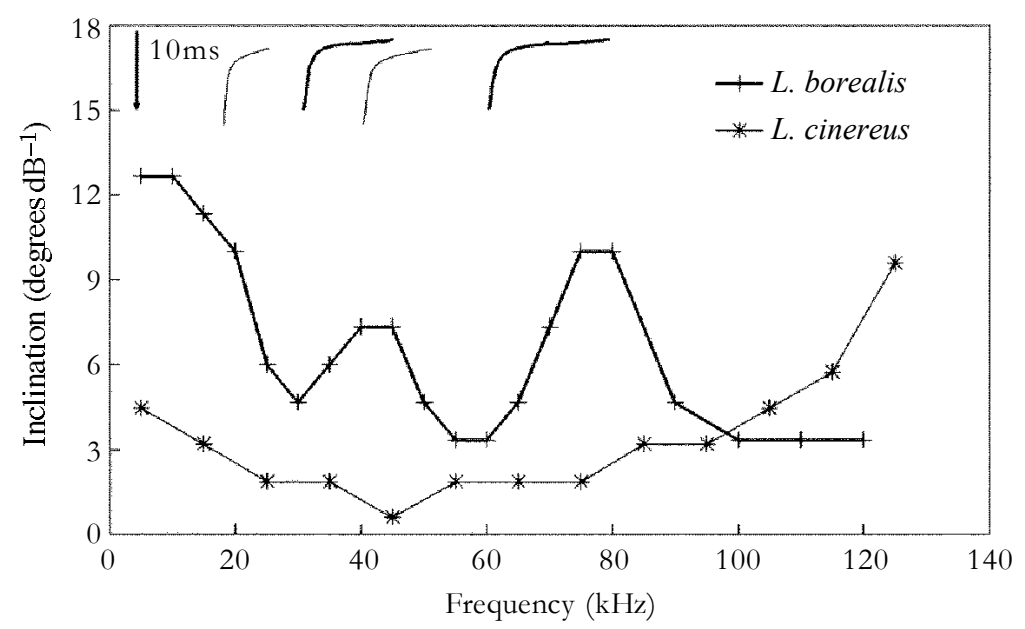

Fig. 9. Inclination of the IID frequency display (refer to Fig. 3) at the frontal position in Lasiurus cinereus and Lasiurus borealis. Schematic echolocation calls are supplied for correlation with the curves.

particularly emballonurids and molossids. A close relationship between pinna features and echolocation calls was also evident in vespertilionids that depend upon narrower bandwidth calls to search for airborne prey. For example, in Lasiurus borealis and Lasiurus cinereus, the highest slope of the IID frequency display and the HIID appeared at the first and/or second harmonic (fundamental=first harmonic) of their echolocation calls (Fig. 9). Furthermore, in L. borealis, $-3 \mathrm{~dB}$ acceptance angle dropped at $40 \mathrm{kHz}$ to a level not otherwise reached until above $80 \mathrm{kHz}$.

Sometimes we found a clear relationship between echolocation call features and pinna features, and at other times we did not. The Noctilionidae provide a clear example. In Noctilio albiventris, there were clear IID peaks at the spectral range of their echolocation calls (Fig. 11C) and the IID frequency displays were also comparable, reaching a steep inclination $\left(<1.9 \mathrm{degrees}^{-1}\right)$ at the forward position above $55 \mathrm{kHz}$. In Noctilio leporinus, however, there was no evident relationship between ear characteristics and acoustic features of search-phase echolocation calls. The IID gradually increased from $20 \mathrm{~dB}$ at $25 \mathrm{kHz}$ to $30 \mathrm{~dB}$ at $85 \mathrm{kHz}$ and neither $-3 \mathrm{~dB}$ acceptance angle nor pinna gain was conspicuously related to the echolocation calls.

Among the emballonurids, external ear dimensions showed a non-significant trend to correlate with the dominant spectral component of the echolocation calls (Fig. 7C,D). Taphozous hildegardae showed an HIID of above $30 \mathrm{~dB}$ between 15 and $55 \mathrm{kHz}$ and the IID frequency display was steep $\left(1.9\right.$ degreesdB $\left.{ }^{-1}\right)$ between 25 and $65 \mathrm{kHz}$, becoming locally shallow again between 75 and $105 \mathrm{kHz}$. Both variables matched with the biosonar calls $(35-25 \mathrm{kHz})$. In Saccopteryx bilineata, the IID showed a maximum of $27 \mathrm{~dB}$ at $45-55 \mathrm{kHz}$ and the IID frequency display was steepest (4.5-1.9degreesdB ${ }^{-1}$ ) between 45 and $95 \mathrm{kHz}$, the main call component being around $45-50 \mathrm{kHz}$. The pinnae of Rhynchonycteris naso showed a local increase in directionality (decrease in $-3 \mathrm{~dB}$ 


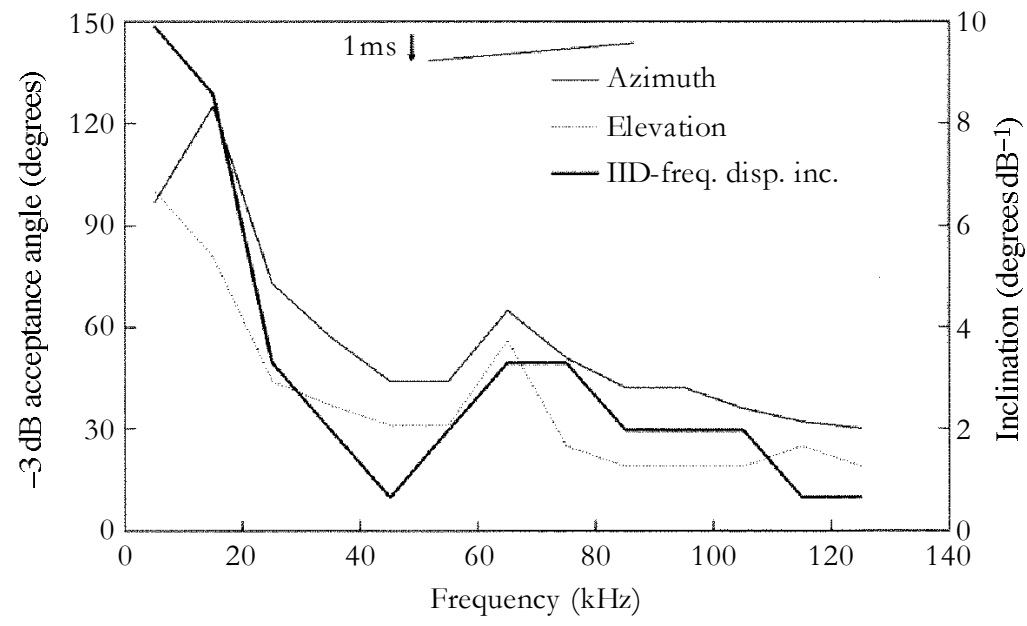

Fig. 10. $-3 \mathrm{~dB}$ acceptance angles in azimuth and elevation and the inclination of the IID frequency display (refer to Fig. 3) in Myotis evotis. The local minima of $-3 \mathrm{~dB}$ acceptance angle at $45-55 \mathrm{kHz}$ affected the IID frequency display, which became considerably steeper in this range (IID freq. disp. inc., IID frequency display inclination). A diagram of a call sonagram is given.

acceptance angle) at the lower harmonic of its echolocation call and the highest pinna gain $(11 \mathrm{~dB})$ was located at the frequency of the FM part of the same harmonic $(25-35 \mathrm{kHz})$. The IID frequency display was relatively unspecific, increasing in absolute value and steepness towards $95 \mathrm{kHz}$. We found the peak in IID $(27 \mathrm{~dB})$ at approximately $85 \mathrm{kHz}$ (FM of the higher harmonic). Finally, in Peropteryx macrotis the maximum IID $(29 \mathrm{~dB})$ lay at $55 \mathrm{kHz}$, above which the IID frequency display was steepest (1.9 degreesdB ${ }^{-1}$ ).

In molossids, the obvious correlation of pinna dimensions (particularly height) with frequency of main call energy was not statistically significant (Fig. 7C,D). The large ears of Otomops martiensseni produced a pinna gain of $12 \mathrm{~dB}$ at $5 \mathrm{kHz}$ and a local minimum in $-3 \mathrm{~dB}$ acceptance angle at $15 \mathrm{kHz}$ which parallels the audible echolocation calls $(17-10 \mathrm{kHz})$. Similar drops were evident in the $-3 \mathrm{~dB}$ acceptance angle of Tadarida pumila at $55 \mathrm{kHz}$ and $85-95 \mathrm{kHz}$. The HIID reached above $25 \mathrm{~dB}$ between 45 and $85 \mathrm{kHz}$ and the IID frequency display was steepest $\left(\leqslant 1.9 \operatorname{degrees} \mathrm{dB}^{-1}\right)$ at the frontal position between 45 and $65 \mathrm{kHz}$ and again at $95-115 \mathrm{kHz}$. Thus, for this species we predict echolocation call frequencies between 35 and $55 \mathrm{kHz}$ with a possible second harmonic (Table 1). Tadarida brasiliensis and T. macrotis showed maxima of the IID $(25 \mathrm{~dB}$ and $27 \mathrm{~dB}$ respectively) and of the frontal inclination of the IID frequency display (0.6degrees $\mathrm{dB}^{-1}$ and 1.9 degrees $\mathrm{dB}^{-1}$ respectively) at the dominant component of their echolocation calls $(45 \mathrm{kHz}$ and approximately $25 \mathrm{kHz}$ respectively). The IID frequency display looked comparable in both species, with T. brasiliensis (Fig. 8C) showing the peak slightly higher than $T$. macrotis.

As in T. pumila, we found no published information about the echolocation calls of 

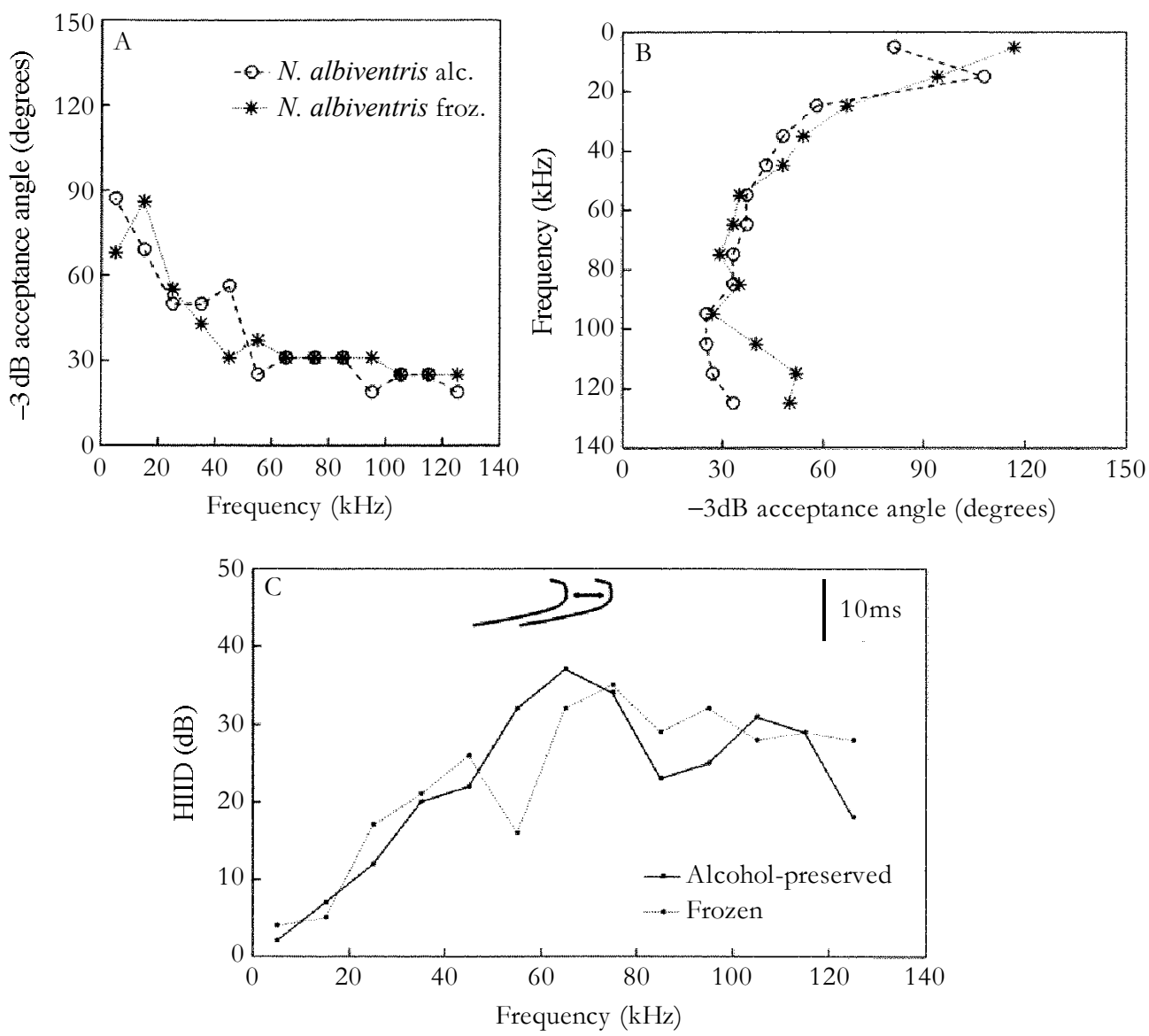

Fig. 11. $-3 \mathrm{~dB}$ acceptance angles in elevation (A) and azimuth (B) and highest interaural intensity difference (HIID; C) in two Noctilio albiventris, an alcohol-preserved (alc.) and a frozen (froz.) specimen. Schematic sonagrams are presented in C.

Mormopterus jugularis and Molossus pretiosus. The ear data for these species suggest that several spectral regions are important in the echolocation of these bats. Mormopterus jugularis showed minima in the $-3 \mathrm{~dB}$ acceptance angle $\left(<60^{\circ}\right.$ in elevation, $<40^{\circ}$ in azimuth) between 55 and $95 \mathrm{kHz}$. This also affected the IID, showing maxima (25-30dB) and highest lateral changes per angular displacement $\left(\leqslant 1.9\right.$ degreesdB $\left.^{-1}\right)$ in the same spectral region. We expect this species to echolocate with harmonic calls dominated by a $55 \mathrm{kHz}$ component. In M. pretiosus the pinna gain $(12 \mathrm{~dB}$ at $25 \mathrm{kHz}$ and $10 \mathrm{~dB}$ at $55 \mathrm{kHz})$ and the slope of the IID frequency display at the frontal position (1.9degreesdB ${ }^{-1}$ between 35 and $85 \mathrm{kHz}$ ) suggest broad-band calls with possible harmonic components at 30 and $60 \mathrm{kHz}$.

The rhinopomatid Rhinopoma hardwickei showed a decrease of the $-3 \mathrm{~dB}$ acceptance angle at $35 \mathrm{kHz}$, coinciding with the main (second harmonic) component of its echolocation calls and the frequency of best hearing. The acceptance angles increased at 
$45 \mathrm{kHz}$. Furthermore, the IID reached a maximum of $30 \mathrm{~dB}$ at this frequency, only exceeded by a second peak $(32 \mathrm{~dB})$ at $85 \mathrm{kHz}$. In general, the IID frequency display (peak and inclination) seemed to be matched to a spectral component at $70-80 \mathrm{kHz}$, coinciding with the fourth harmonic of the call.

\section{The CF or high-duty-cycle echolocating bats}

Unlike the other species in the Mormoopidae, Pteronotus parnellii uses long, narrowbandwidth, high-duty-cycle search-phase echolocation calls to detect fluttering targets. We found an obvious relationship between echolocation call characteristics and pinna structure. The IID frequency display showed a marked increase in steepness from $3.5 \mathrm{degrees} \mathrm{dB}^{-1}$ to $1.9 \mathrm{degrees}^{-1}$ at approximately $60 \mathrm{kHz}$ and the absolute peaks in sensitivity corresponded to the spectral positions of harmonics of the echolocation calls (see Fig. 12E).

The relationship between pinna features and echolocation calls, however, was most evident in the rhinolophids and hipposiderids. Rhinolophids showed a distinct matching of dominant echolocation frequencies and ear characteristics. For example, in Rhinolophus rouxi, a pinna gain of $14 \mathrm{~dB}$ coincided with the maximum IID $(34 \mathrm{~dB})$ at $75 \mathrm{kHz}$; pinna gain rose to $24 \mathrm{~dB}$ at $85 \mathrm{kHz}$. The central inclination of the IID frequency display (Fig. 8F) reached 1.9 degrees $\mathrm{dB}^{-1}$ above $35 \mathrm{kHz}$ with a local increase to $0.6 \mathrm{degreesdB}-1$ at $75-95 \mathrm{kHz}$. In Rhinolophus clivosus, the IID reached peak values (approximately $30 \mathrm{~dB}$ ) between 75 and $105 \mathrm{kHz}$, and above $75 \mathrm{kHz}$ the IID frequency display had an inclination of $0.6 \mathrm{degrees} \mathrm{dB}^{-1}$ at $0^{\circ}$ azimuth and closely resembled the plot for $R$. rouxi but with the peak shifted to $95 \mathrm{kHz}$. Echolocation calls of $R$. clivosus have the dominant harmonic between $70 \mathrm{kHz}(R$. c. deckeni) and $100 \mathrm{kHz}(R$. c. clivosus; J. D. Pye, personal communication). In Rhinolophus eloquens, the peak IIDs occurred at $35 \mathrm{kHz}(35 \mathrm{~dB}), 55-60 \mathrm{kHz}$ and $85 \mathrm{kHz}(28 \mathrm{~dB})$, with drops of $5-10 \mathrm{~dB}$ between the peaks. The $-3 \mathrm{~dB}$ acceptance angles showed the usual decrease to a low of $38^{\circ}$ at $45-55 \mathrm{kHz}$ in elevation and $\leqslant 30^{\circ}$ at $45-65 \mathrm{kHz}$ in azimuth, but with a subsequent gradual increase to $62^{\circ}$ (elevation) and $42^{\circ}$ (azimuth) at $85 \mathrm{kHz}$. This produced an IID frequency display comparable to that of $R$. rouxi but with the peak shifted to $45 \mathrm{kHz}$ so that the highest change of IID per degree $\left(0.6\right.$ degrees $\left.\mathrm{dB}^{-1}\right)$ extended from 45 to $65 \mathrm{kHz}$. The biosonar signals of $R$. eloquens should have the dominant component between 45 and $55 \mathrm{kHz}$.

Hipposiderids had pinna dimensions and echolocation call frequencies that were significantly correlated (Fig. 7C,D). The main component of the sonar signals of Cloeotis percivali lay at $212 \mathrm{kHz}$ (probably the fifth harmonic), but we found distinct features associated with the pinnae at $165 \mathrm{kHz}$ (possibly the fourth harmonic), where pinna gain reached its maximum of $20 \mathrm{~dB}$, and the HIID amounted to $28 \mathrm{~dB}$, a value only exceeded at $125 \mathrm{kHz}(30 \mathrm{~dB})$. The IID frequency display is clearly dominated by the high-frequency range around $170 \mathrm{kHz}$, where the display also reaches its highest inclination (Fig. 3G,H). In Asellia tridens (Fig. 8D), the peak IID (35dB) and a maximum in inclination of the IID frequency display $\left(1.9\right.$ degrees $\left.\mathrm{dB}^{-1}\right)$ coincided with the spectral range of the echolocation calls (the absolute maximum was $0.6 \mathrm{degreesdB}^{-1}$ at $45-65 \mathrm{kHz}$ ). In Hipposideros lankadiva, the elevational $-3 \mathrm{~dB}$ acceptance angle showed a low of $20^{\circ}$ at 

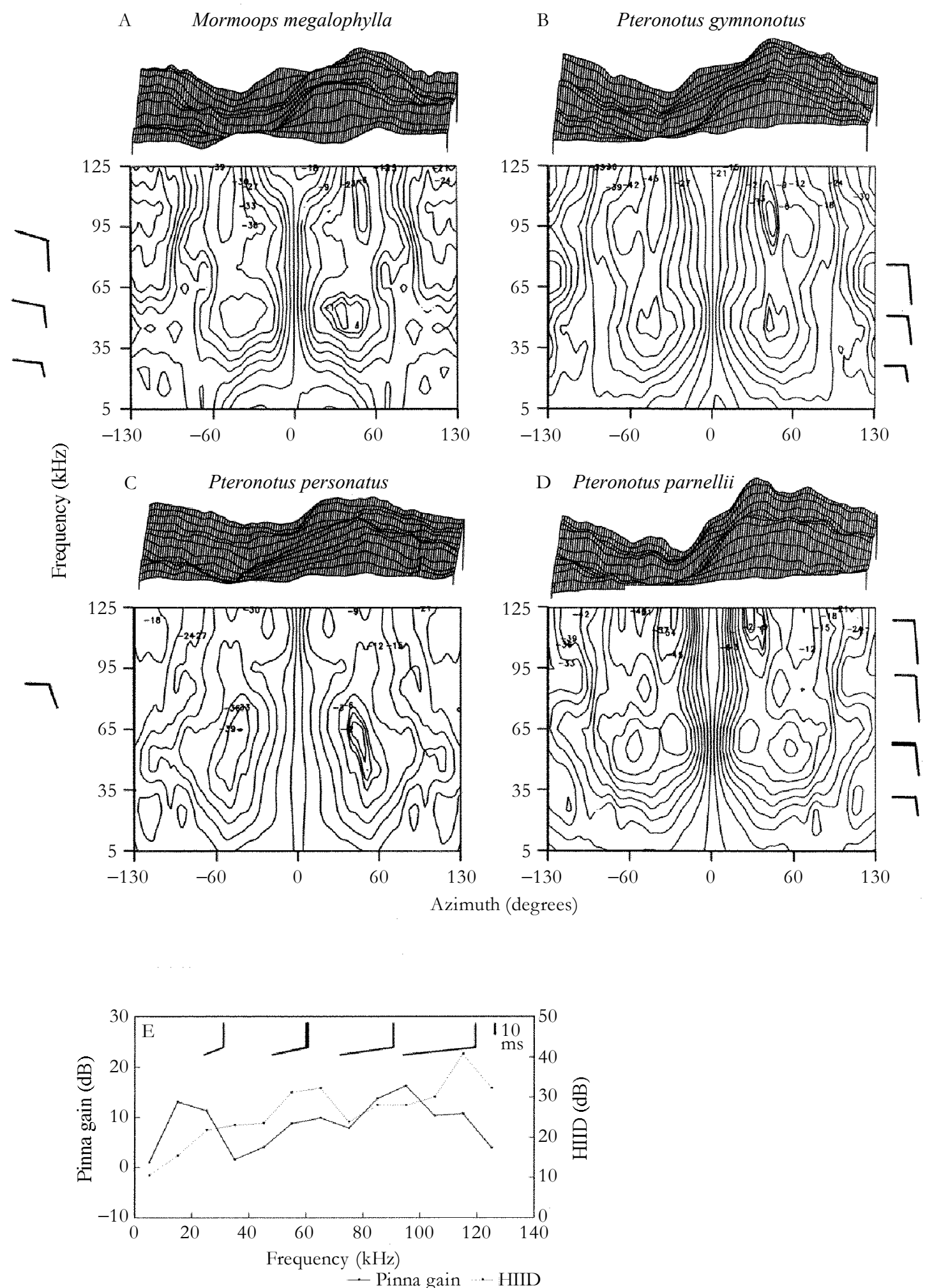

Fig. 12 
Fig. 12. Axonometric (top) and contour line plot (bottom) of the IID frequency displays of the four mormoopids Mormoops megalophylla (A), Pteronotus gymnonotus (B), Pteronotus personatus (C) and Pteronotus parnellii (D). For further explanation, see Fig. 3. (E) Pinna gain and highest interaural intensity difference (HIID) in $P$. parnellii. The species' echolocation call is indicated baside each graph.

$65 \mathrm{kHz}$, followed by a gradual increase to $42^{\circ}$ at $105 \mathrm{kHz}$. Highest inclination of the IID frequency display $\left(0.6\right.$ degrees $\left.\mathrm{dB}^{-1}\right)$ was also located in this spectral range. In Hipposideros caffer, the $-3 \mathrm{~dB}$ acceptance angle reached a minimum of $24^{\circ}$ in elevation (at $145-165 \mathrm{kHz}$ ) and $27-28^{\circ}$ in azimuth (at $135-155 \mathrm{kHz}$ ), followed by an increase in angle of more than $20^{\circ}$. Again, the highest inclination of the IID frequency display (1.9degrees $\left.\mathrm{dB}^{-1}\right)$ occurred in the range of the sonar signal $(145 \mathrm{kHz})$, and in this species additionally at $45-95 \mathrm{kHz}$.

\section{Gleaning bats}

Our data included seven species that hunt by listening for prey-generated sounds: Cardioderma cor, Megaderma lyra (Megadermatidae), Nycteris grandis, Nycteris thebaica (Nycteridae), Antrozous pallidus, Myotis evotis (Vespertilionidae) and Trachops cirrhosus (Phyllostomidae). These are large-eared species and some achieve pinna gains of $15-22 \mathrm{~dB}$ by $15 \mathrm{kHz}$, or in C. cor $13 \mathrm{~dB}$ at $5 \mathrm{kHz}$ (Fig. 13). Trachops cirrhosus showed $5-10 \mathrm{~dB}$ pinna gain between 5 and $95 \mathrm{kHz}$.

In general, these bats were distinctive because of the high directionality achieved at lower frequencies relative to the bats that depended upon echolocation to find their prey. Trachops cirrhosus showed an HIID of $27 \mathrm{~dB}$ at $5 \mathrm{kHz}$, the highest value we encountered

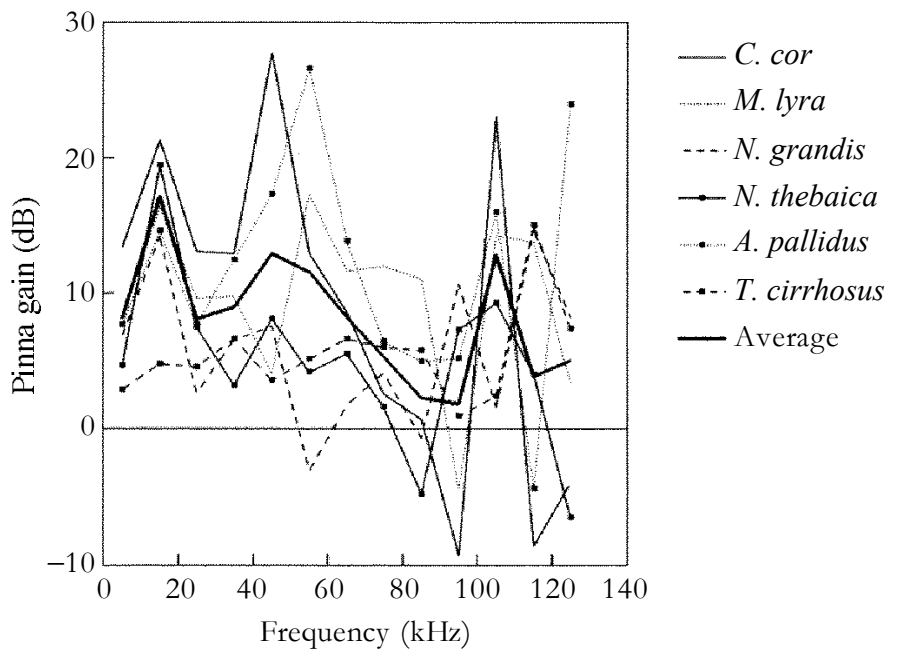

Fig. 13. Pinna gain curves of passive listening bats (Cardioderma cor, Megaderma lyra, Nycteris grandis, Nycteris thebaica,Antrozous pallidus, Trachops cirrhosus). An average was calculated from the values for all species except T. cirrhosus. Calculation of pinna gain is explained in Methods, data analysis. 


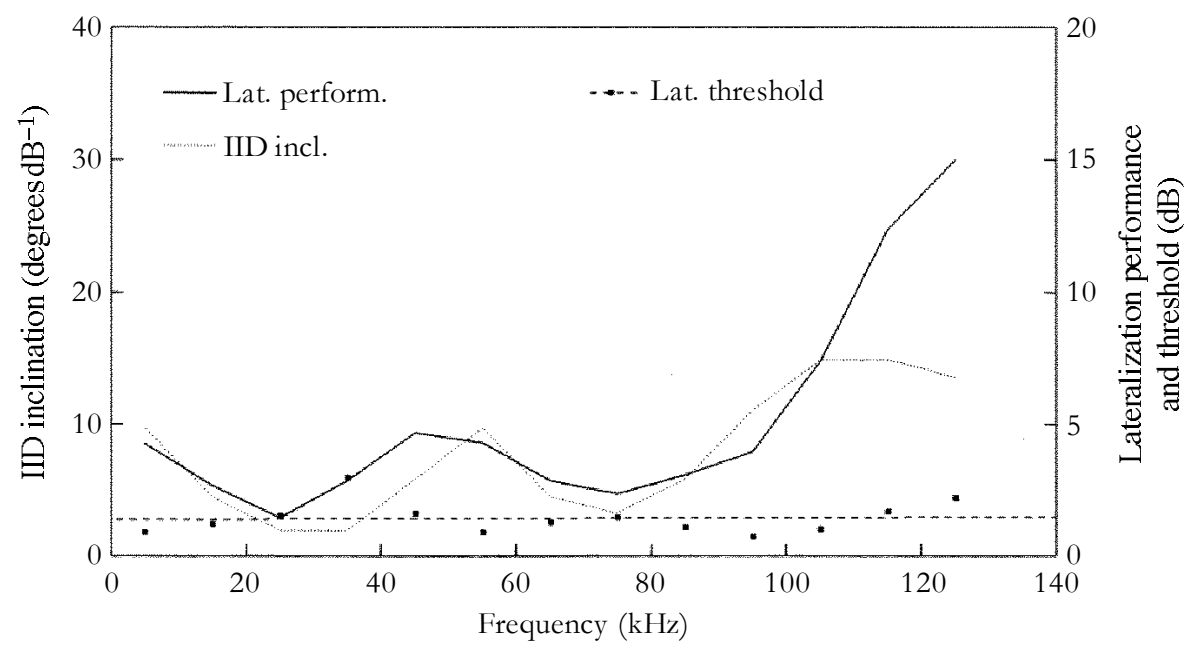

Fig. 14. Pure-tone lateralization performance (Lat. perform after Witzke, 1989), inclination of the IID frequency display at the frontal direction (IID incl.; refer to Fig. 3 for further explanation) and derived absolute pure-tone lateralization threshold in $\mathrm{dB}$ (Lat. threshold) in Megaderma lyra. The latter was derived by division of the first by the second. The lateralization threshold $(1.4 \pm 0.6 \mathrm{~dB})$ is independent of frequency.

in this study at the lowest tested frequency. In T. cirrhosus we found an inclination of the IID frequency display of 1.9 degreesdB $\mathrm{dB}^{-1}$ at $0^{\circ}$ azimuth between $5 \mathrm{kHz}$ and $85 \mathrm{kHz}$. Comparable inclination values for most non-passive listening bats were less than 2 degreesdB $\mathrm{d}^{-1}$ only above $45 \mathrm{kHz}$ and Myotis evotis was more similar to this group (Fig. 10). Cardioderma cor and N. grandis reached this value at $35 \mathrm{kHz}, M$. lyra, $N$. thebaica and A. pallidus at $25 \mathrm{kHz}$, suggesting good lateralization perfomance at low frequencies. The inclination showed prominent local drops at intermediate frequencies in $N$. grandis (1.9degreesdB $\mathrm{dB}^{-1}$ at $25-35 \mathrm{kHz}$ and above $85 \mathrm{kHz} ; 19.3$ degreesdB ${ }^{-1}$ at $45 \mathrm{kHz}), N$. thebaica $\left(1.9\right.$ degreesdB ${ }^{-1}$ at $35-75 \mathrm{kHz} ; 10$ degreesdB $^{-1}$ at $95 \mathrm{kHz}$ ) and M. lyra (1.9degreesdB $\mathrm{dB}^{-1}$ at $25-35 \mathrm{kHz}, 10$ degreesdB ${ }^{-1}$ at $55 \mathrm{kHz}$; Fig. 14).

\section{Discussion}

\section{Methodological considerations}

The methods used to prepare our specimens meant that our measurements were unaffected by the method of preservation used. In Eptesicus fuscus, Noctilio albiventris and Phyllostomus discolor, we compared the two methods of preservation and found $-3 \mathrm{~dB}$ acceptance angles and HIIDs (Fig. 11A-C) reproducible in different preparations.

Differences found by P. A. Schlegel (unpublished observations) between recently dead and preserved $R$. rouxi were comparable in size to differences found between repeated measurements taken on the same specimen. The general characteristics appear unchanged unless the pinna starts drying out or is drastically changed in shape. Since desiccation of the pinnae had been shown to increase amplification significantly at higher frequencies 
$(>70 \mathrm{kHz})$, we used short data collection times $(40 \mathrm{~min})$ to ensure that the preparation did not dry out.

Our data compare well with data obtained from recently dead or live animals. Electrophysiological measurements on Rhinolophus ferrumequinum show a stable position of the acoustic axis at $30 \mathrm{kHz}, 60 \mathrm{kHz}$ and $80 \mathrm{kHz}$ within an individual, differing slightly between individuals (15-45 azimuth, 30-60 elevation; Neuweiler, 1970). Comparably, at these frequencies, we found only minor changes in axis position in $R$. rouxi ( $>25 \mathrm{kHz}: \pm 4^{\circ}$ elevation; $\pm 8^{\circ}$ azimuth), $R$. eloquens $\left(>15 \mathrm{kHz}: \pm 10^{\circ}\right.$ elevation; $\pm 15^{\circ}$ azimuth) and $R$. clivosus ( $>15 \mathrm{kHz}: \pm 7^{\circ}$ elevation; $\pm 8^{\circ}$ azimuth). Electrophysiologically obtained directionality patterns measured at $83.3 \mathrm{kHz}$ in Rhinolophus ferrumequinum (Neuweiler, 1970) and at $20 \mathrm{kHz}, 65.2 \mathrm{kHz}$ and $80 \mathrm{kHz}$ in $R$. rouxi (P. A. Schlegel, unpublished results; R. B. Coles, A. Guppy and P. A. Schlegel, unpublished results) look very much like our results in the same or other rhinolophid and hipposiderid species (e.g. Hipposideros caffer at $75 \mathrm{kHz}$, Fig. 1C). In rhinolophids, in the range of their sonar signals, we found $-3 \mathrm{~dB}$ acceptance angles (approximately $20^{\circ}$ in azimuth and $30^{\circ}$ in elevation) that agree with data from $R$. ferrumequinum (Neuweiler, 1970) and behavioural results obtained in the same species (Grinnell and Schnitzler, 1977). The HIID values we calculated for R. rouxi (34 dB) and R. eloquens ( $35 \mathrm{~dB}$; see Table 1) again compare well with values measured on live $R$. ferrumequinum (approximately 30dB; Neuweiler, 1970) and R. rouxi (40dB; Schlegel, 1977b).

In two FM bats we found HIID values $(20 \mathrm{~dB}$ at $65 \mathrm{kHz}$ Myotis nigricans; $22 \mathrm{~dB}$ at $45 \mathrm{kHz} M$. evotis) that are confirmed by electrophysiologically measured values published by Shimozawa et al. (1974) for Myotis grisescens (approximately $25 \mathrm{~dB}$ at $35 \mathrm{kHz}$ and $55 \mathrm{kHz}$ ) and $M$. lucifugus (approximately $15 \mathrm{~dB}$ at $75 \mathrm{kHz}$ and $95 \mathrm{kHz}$ ).

The actual mounting of the specimen in the centre of the scanned sphere was not completely reproducible. This meant that the position of the acoustic axis showed more variation and this is the reason why we did not compare absolute positions of this axis between preparations. All three measured Lasiurus borealis differed slightly in the position of the acoustic axis, but showed comparable $-3 \mathrm{~dB}$ acceptance angles and a marked narrowing of the angle in the $35-40 \mathrm{kHz}$ range, coinciding with the spectral position of the dominant harmonic in the echolocation calls.

In L. borealis and up to $125 \mathrm{kHz}$ in Cloeotis percivali we collected data from both ears and the comparable results justified the calculations of variables that depended upon sagittal symmetry of the sound pressure transformation (e.g. IIDs).

\section{Contribution of pinna effects to sound localization}

Most mammals, especially echolocating bats, depend on accurate localization of sound sources. We found that bat pinnae were increasingly directional at frequencies above $5 \mathrm{kHz}$ (Figs 2, 5), and that the position of the acoustic axis shifted towards the sagittal midline and higher elevations, eventually reaching a plateau (Fig. 4). The frequencydependent shift of the acoustic axis might help monaural localization of frequencystructured sounds, but localization performance improves considerably when completed binaurally (Gourevitch, 1987). Since we could only measure intensity, our estimates of 
lateralization performances do not consider simultaneous analysis of time and intensity differences.

Because of basic acoustical principles (Fletcher and Thwaites, 1979), we could not find a clear peak in the sound pressure transformation at lower frequencies in small-eared species. The characteristics of the large external ears of Plecotus auritus (Coles et al. 1989), Macroderma gigas and Nyctophilus gouldii (Guppy and Coles, 1988b) accurately match the behaviour of mathematical horns of similar dimensions. We therefore refrain from discussing the results of our study in physical terms and turn our attention to the biological relevance of the measurements.

The directionality of the echolocation system has been measured previously using different methods in a variety of bats (e.g. in Myotis lucifugus and Corynorhinus townsendii, Grinnell, 1963; Eptesicus fuscus, Carollia brevicauda and Pteronotus parnellii, Jen and Chen, 1988; Myotis grisescens, Shimozawa et al. 1974; Rhinolophus ferrumequinum, Grinnell and Schnitzler, 1977; Schnitzler and Grinnell, 1977). In all species, hearing becomes more directional with increasing frequencies. Myotis lucifugus reaches $-3 \mathrm{~dB}$ acceptance angles of $50^{\circ}$ above $40 \mathrm{kHz}$, the larger ears of Corynorhinus townsendii achieve values of $30^{\circ}$ above $50 \mathrm{kHz}$ (Grinnell, 1963), a value also found by Coles et al. (1989) in Plecotus auritus. Similar values were reported for the three species measured by Jen and Chen (1988). In $M$. griesecens and $R$. ferrumequinum, the directionality of sound emission and hearing combine to produce a steep increase of the total directionality of the sonar system in front of the bat (Shimozawa et al. 1974; Grinnell and Schnitzler, 1977). Highest interaural intensity differences (>30dB) occur at around $40 \mathrm{kHz}$ in E. fuscus, C. brevicauda, M. lucifugus and C. townsendii; values of 20-30dB are reached in $P$. parnellii and $M$. grisescens. Up to $40 \mathrm{~dB}$ IID can be found in $R$. ferrumequinum (Schlegel, 1977 b). IIDs change at a rate of up to 1.7 degreesdB $^{-1}$ in M. grisescens, and Grinnell (1963) reported single units in the inferior colliculus with slopes of 0.1 degreesdB ${ }^{-1}$ in $M$. lucifugus. All these data compare favourably with our measurements, although the steepest slopes we encountered were $\geqslant 0.6$ degrees $\mathrm{dB}^{-1}$.

If bats, like other mammals, have a minimal binaurally detectable intensity difference of $1 \mathrm{~dB}$ (approximately $1 \mathrm{~dB}$ at $1 \mathrm{kHz}$ in humans, Mills, 1960, and cats, Wakeford and Robinson, 1974), most species should detect differences of less than $5^{\circ}$ in lateral position of pure-tone sources, at certain frequencies. In some species, an approximately $1^{\circ}$ resolution is predicted from our data (e.g. Rhinolophus rouxi at 85-95kHz, Fig. 8F; cf. Schlegel, 1977b). A value of 1.5-0.25 has been suggested for M. lucifugus (Jen, 1980). In Megaderma lyra, the pure-tone lateralization performance has been measured behaviourally (Witzke, 1989), and the performance curve follows the course of the frontal inclination in the IID frequency display, reflecting the amount of intensity change for a given change in position and a given frequency. The division of the lateralization performance curve (in degrees) by the inclination curve (in degreesdB ${ }^{-1}$ ) results in a frequency-independent lateralization threshold which has a value of $1.4 \pm 0.6 \mathrm{~dB}$ (Fig. 14). This value is remarkably close to the $1 \mathrm{~dB}$ assumed above and, using earphones, one could verify experimentally that this is indeed the minimum binaural intensity difference discernible by $M$. lyra. These results strongly suggest that bats depend upon intensity cues for sound lateralization. This is further substantiated by the fact that other mammals need 
decreasing intensity but increasing temporal disparities for sound lateralization at higher frequencies $(0.5-3 \mathrm{kHz}$, measured in cats, Wakeford and Robertson, 1974). In M. lyra, the lateralization performance and the slope of the IID frequency display match over the whole frequency range measured. If other bats (such as Artibeus lituratus, Nycteris grandis, Nycteris thebaica and Taphozous hildegardae, see Table 1, VAR) use primarily intensity cues for pure-tone lateralization, we expect their performances to drop at decreasing slopes of the IID frequency display, as in M. lyra.

The three specimens of E. fuscus we measured reached highest inclinations of the IID frequency display of $1.9 \mathrm{degrees} \mathrm{dB}^{-1}$ in the range of their echolocation calls. A binaural detection threshold of $1.4 \mathrm{~dB}$ should allow this species to differentiate pure-tone sources separated by $2.6^{\circ}$. Peff and Simmons (1971) reported horizontal angle resolutions of 6-8 in E. fuscus and $4-6^{\circ}$ in Phyllostomus hastatus. In later experiments, employing a different arrangement, however, E. fuscus could discriminate $1.5^{\circ}$ in $75 \%$ of the experiments (Simmons et al. 1983). The authors discuss these results on the basis of time rather than intensity disparities. Our data suggest that the same performance could be achieved with the use of intensity cues.

\section{Specialization of the mode of orientation relates to ear properties}

The data presented here reveal a general trend in all investigated families. Bat species, emphasizing a spectral band in their echolocation calls, tend to show matching specializations of calls and pinnae. In the vespertilionid Miniopterus natalensis, for example, the lowest range of the echolocation calls, which contains most signal energy, coincides with the area of best hearing, the spectral range of highest interaural intensity difference and the highest IID change per degree. In this and other species (L. borealis, $R$. rouxi, H. lankadiva, etc.) there is obvious matching of pinnae and echolocation calls.

In the Megachiroptera, only two species studied use biosonar and produce short, broadband signals in a way that differs from that in the Microchiroptera (Suthers, 1988). We found no evidence of pinna specialization in echolocating Megachiroptera. The large head and pinnae of Pteropus giganteus coincided with a relatively smooth rise in IID with azimuth (Fig. 6A). The data from Rousettus amplexicaudatus showed no clear pattern, but $R$. aegyptiacus showed directionality and IID patterns comparable to those of microchiropteran bats (Fig. 6B). The Megachiroptera appear to be 'ear generalists' not differing substantially from other mammals such as cats (Irvine, 1987; Martin and Webster, 1989).

As noted above, echolocating Michrochiroptera can be grouped according to their use of echolocation and their approach to foraging (Table 2). The majority of species use echolocation for medium- to short-range target or obstacle detection. Species foraging at short range, feeding on insects, nectar and pollen, fruit or blood, emit short, broad-band echolocation calls with no clear dominant frequency. In these species, including representatives of the Molossidae, Mormoopidae, Phyllostomidae and Vespertilionidae, we found moderate directionality, IID and pinna gain, generally confirming our hypothesis. But there were hints of specializations in the phyllostomids Desmodus rotundus and Trachops cirrhosus. In D. rotundus, locally increased directionality of pinna sound pressure transformation at $25-35 \mathrm{kHz}$ produced a local increase of the pinna 
M. K. OBRIST AND OTHERS

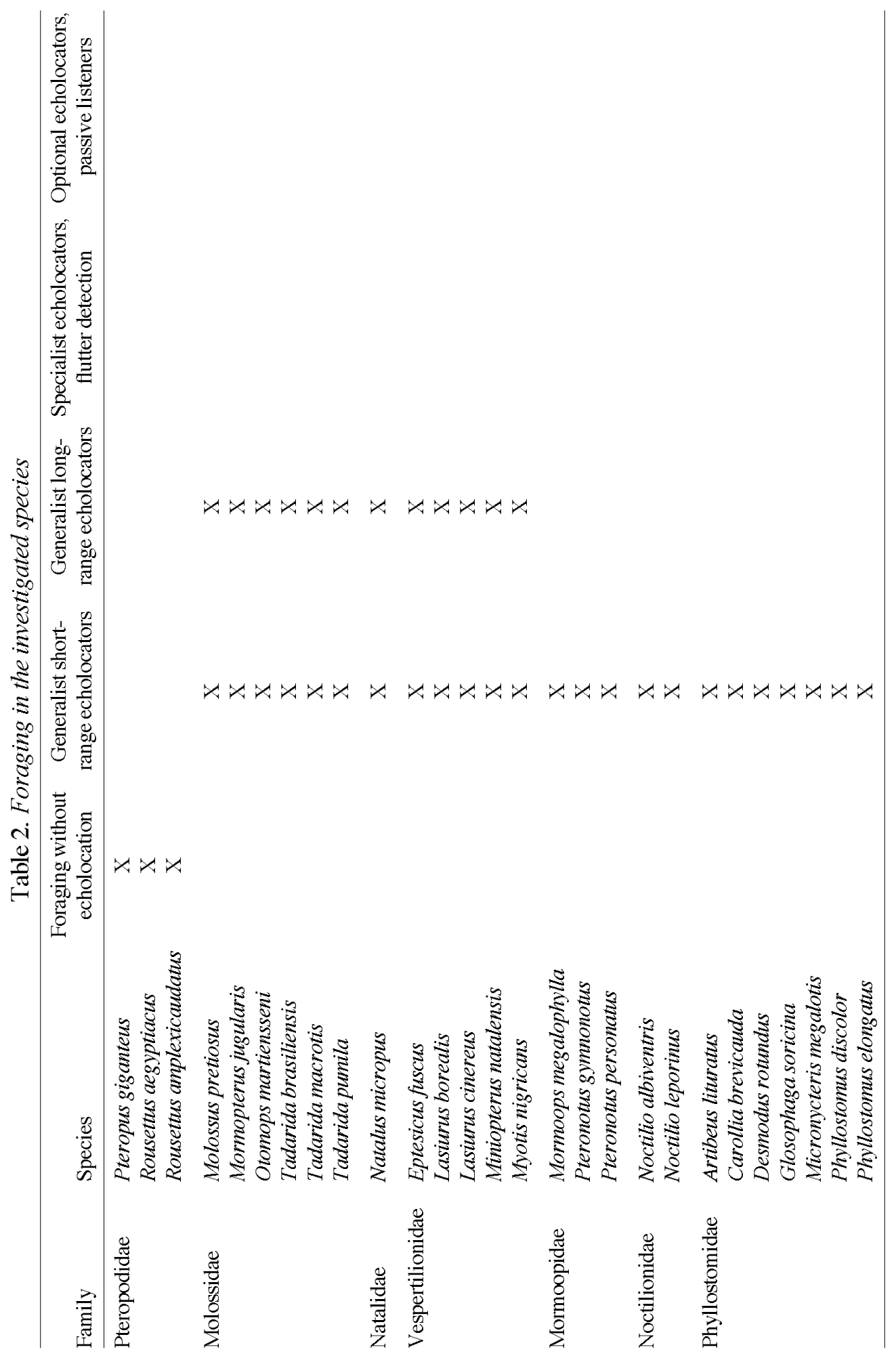


What ears do for bats

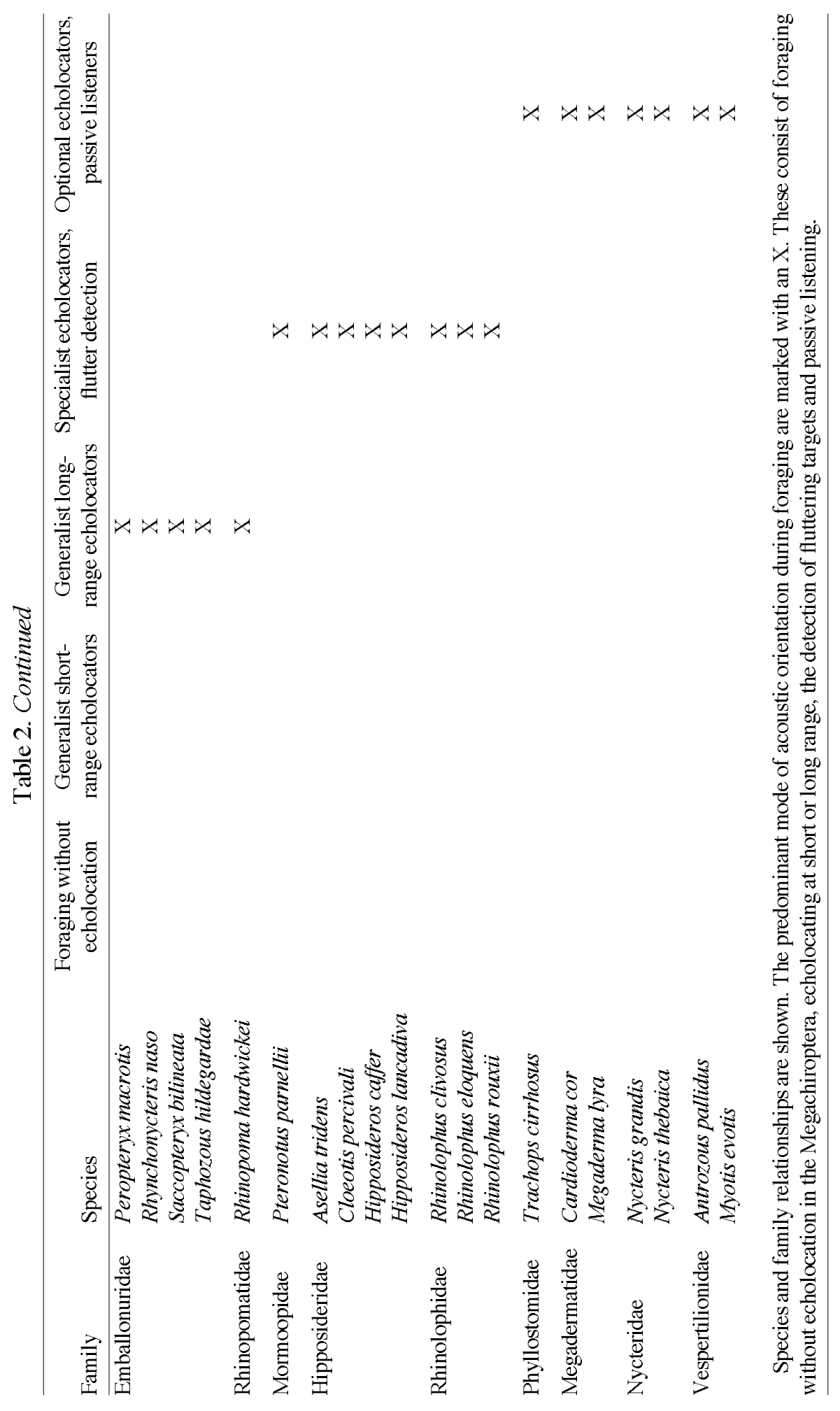


gain, coinciding with the sensitivity of neurones in the inferior colliculus that show high sensitivity to breathing noises, containing energy in the range of $25-35 \mathrm{kHz}$ (Schmidt et al. 1991). Together, these results strongly suggest that $D$. rotundus depends upon preygenerated noises to find its targets. The large pinnae of $T$. cirrhosus should mean large pinna gain at low frequencies, but we found a steep IID slope over the whole frequency range. Trachops may not need high pinna gain to detect loudly calling frogs (Tuttle and Ryan, 1982), a situation demanding accurate localization. The high inclination of the IID frequency display allows accurate lateralization, and the exceptionally high maximum IID at frequencies of frog calls $(<4 \mathrm{kHz}$, Tuttle and Ryan, 1982; Tuttle et al. 1985) can enhance this ability. Other species that locate prey by prey-generated noises (Megadermatidae and Nycteridae, see below) are probably not confronted with the problem of localizing a sound source of limited bandwidth. Rustling sounds have a much broader bandwidth than frog calls so the pinnae improve directional hearing and especially amplify at slightly higher frequencies.

Many species are flexible in their sonar behaviour (e.g. Obrist, 1989) and may adapt their signal structure to extend their sonar range (Simmons and Stein, 1980). This is achieved by increasing call duration and limiting energy to a narrow spectral band. Many insectivorous bats change their call design drastically over the course of an attack or an insect pursuit. For example, during a long-range search, L. borealis uses predominantly narrow-band signals (Obrist, 1989) and its pinna properties are correlated with the dominant spectral sonar component (Fig. 9). Matching of the external ears to the frequencies dominating echolocation calls is reflected in many species, and has been assumed in species not considered here (e.g. Euderma maculatum, Guppy and Coles, 1988a). Bats with low-frequency sonar calls should require large pinnae, but this is not the case in Lasiurus cinereus where the pinna matches the second harmonic of the call. The occurrence of $L$. cinereus at high latitudes may mean keeping ears small to minimize heat loss, and matching the pinna to the second harmonic may reflect this environmental constraint. Since this species also occurs in tropical areas, the strength of this relationship would be questionable.

Specialization for long-range target detection becomes clearer in the high-flying species of the Emballonuridae and especially some Molossidae, both showing more obvious correspondence between directionality patterns and echolocation calls. In some emballonurids, pinna features best matched the FM part of their vocalizations, and in other species they best matched the second harmonic of the call. In the Molossidae, ear features were distinctly related to call characteristics. In the three species for which echolocation calls are known, the IID shows peaks and steepest slope at the dominant sonar component (Fig. 8C). Molossids are presumed to hunt insects at high altitudes in relatively fast flight and to use sonar signals of narrow bandwidth (Simmons et al. 1978) to increase effective range. The rhinopomatid Rhinopoma hardwickei uses comparable foraging and echolocation (Simmons et al. 1984) and shows similar ear characteristics, which should favour the localization of signals, used in long-range target detection.

Two Old World families, the Hipposideridae and the Rhinolophidae, and one representative of the New World Mormoopidae (P. parnellii) have evolved anatomical 
and physiological specializations (e.g. Bruns et al. 1976) to detect fluttering insects. These specialisations allow decoding of frequency and amplitude modulations 'imprinted' at the rate of the insect wingbeat on the echo returning to the bat (e.g. Kober and Schnitzler, 1990). Using an analogy from the visual system, the hearing world of these bats probably has a slightly 'monochromatic' touch, and the characteristics of their pinnae reflect this view. We found an unmistakable 'tuning' of the external ears to the CF echolocation call components in Hipposideridae and Rhinolophidae (Fig. 8D-F). The same pattern does not fit all species, however, for some exhibit peak pinna gain, others highest interaural intensity differences and still others steepest IID in the spectral range of the CF part of their echolocation calls. The IID frequency display showed the most consistent specializations, again substantiating the importance of interaural intensity differences for echolocation. However, bats in these families have conspicuous ear movements (e.g. Pye and Roberts, 1970), correlated with sound emissions. These movements seem to be crucial for target localization in the vertical plane (Mogdans et al. 1988). We predict that the movements will affect the IID available to the auditory system. An accurate reconstruction of IIDs at different frequencies and at different positions of the pinnae could provide an interesting comparison. Pteronotus parnellii shows an interesting convergence with hipposiderids and rhinolophids, coinciding with specializations in its auditory pathway, which is tuned to the dominant CF harmonic at $60 \mathrm{kHz}$ (Pye, 1980b). The specializations reflect the use of Doppler-shifted echoes to ensure that returning echoes are at the frequency of greatest sensitivity of its auditory system. Our results indicate that the directionality of sound pressure transformation at the external ear and derived qualities such as the interaural intensity difference and pinna gain are also specialized compared with other mormoopids (Fig. 12).

Finally, species that detect and locate targets by listening to prey-generated noises have large ears that strongly amplify frequencies below $15 \mathrm{kHz}$ (Fig. 13). In megadermatids and nycterids, the high slope of the IID frequency display at these frequencies will further improve their localization of sound sources. Arthropods or small vertebrates rustling on a dry substratum create noises with most energy below $25 \mathrm{kHz}$, the spectral range where large pinnae show their advantage in directionality over more orthodox ears (Fig. 13). The matching of directionality, and especially of the IID patterns, with the dominant components of search-phase echolocation calls or prey-generated noises in so many species convinces us of the importance of the external ears for the generation of the intensity cues necessary for sound localization. Pinna structures of bat species reflect the parallel evolution of production, reception and analysis of echolocation sounds and the approach these species have taken to foraging.

Echolocation calls recorded by J. D. Pye were supplied for comparison by the British Library of Wildlife Sounds. We thank M. Licht for his help with figure preparation, Dr P. Witzke for technical assistance and Drs M. Brigham, B. Hickey and D. Pinheiro for helpful comments on the manuscript. This research was made possible by a postdoctoral fellowship of the Swiss National Foundation for the Promotion of Science to M.K.O., an operating grant from NSERC to M.B.F. and the SFB 204 (Gehör) München. 


\section{References}

Anderson, M. B. And RACEY, P. A. (1991). Feeding behaviour of captive brown long-eared bats, Plecotus auritus. Anim. Behav. 42, 489-493.

Balcombe, J. And Fenton, M. B. (1988). Eavesdropping by bats, the influence of echolocation call design and foraging strategies. Ethology 79, 158-166.

Barclay, R. M. R. (1983). Echolocation calls of emballonurid bats from Panama. J. comp. Physiol. A 151, 515-520.

BeLL, G. P. (1982). Behavioural and ecological aspects of gleaning by a desert insectivorous bat, Antrozouspallidus (Chiroptera, Vespertilionidae). Behav. Ecol. Sociobiol. 10, 217-223.

BeLl, G. P. (1985). The sensory basis of prey location by the California leaf-nosed bat Macrotus californicus (Chiroptera: Phyllostomatidae). Behav. Ecol. Sociobiol. 16, 343-347.

BELWOOD, J. J. (1988). Foraging behavior, prey selection and echolocation in phyllostomine bats (Phyllostomidae). In Animal Sonar (ed. P. E. Nachtigall and P. W. B. Moore), pp. 601-605. New York, London: Plenum Press.

Brown, P. E. And Grinnell, A. D.(1980). Echolocation ontogeny in bats. In Animal SonarSystems (ed. R. G. Busnel and J. F. Fish), pp. 355-377. New York: Plenum Press.

Bruns, V., Schnitzler, H.-U., Suga, N., Simmons, J. A., Neuweiler, G. and Möller, J. (1976). Peripheral auditory tuning for fine frequency analysis by the CF-FM bat, Rhinolophus ferrumequinum. I-IV. J. comp. Physiol. 106, 17-125.

COLes, R. B. AND Guppy, A. (1986). Biophysical aspects of directional hearing in the Tammar wallaby, Macropus eugenii. J. exp. Biol. 121, 371-394.

Coles, R. B., Guppy, A., Anderson, M. E. And Schlegel, P. (1989). Frequency sensitivity and directional hearing in the gleaning bat, Plecotus auritus (Linnaeus 1758). J. comp. Physiol. A 165, 269-280.

Faure, P. A., Fullard, J. H. and Barclay, R. M. R. (1990). The response of tympanate moths to the echolocation calls of a substrate gleaning bat, Myotis evotis. J. comp. Physiol. A 166, 843-849.

FENTON, M. B. (1980). Adaptiveness and ecology of echolocation in terrestrial (aerial) systems. In Animal SonarSystems (ed. R. G. Busnel and J. F. Fish), pp. 427-446. New York: Plenum Press.

FENTON, M. B. (1986). Hipposideros caffer (Chiroptera, Hipposideridae) in Zimbabwe, morphology and echolocation calls. J. Zool., Lond. A 210, 347-353.

FENTON, M. B. (1988). Variation in foraging strategies in five species of insectivorous bats implications for echolocation call design. In Animal Sonar (ed. P. E. Nachtigall and P. W. B. Moore), pp. 607-611. New York, London: Plenum Press.

FENTON, M. B. (1990). The foraging behaviour and ecology of animal-eating bats. Can. J. Zool. 68, $411-422$.

Fenton, M. B. AND Bell, G. P. (1981). Recognition of species of insectivorous bats by their echolocation calls. J. Mammal. 62, 233-243.

FieDler, J. (1979). Prey catching with and without echolocation in the Indian False Vampire (Megaderma lyra). Behav. Ecol. Sociobiol. 6, 155-160.

Fletcher, N. H. And Thwaites, S. (1979). Physical models for the analysis of acoustical systems in biology. Q. Rev. Biophys. 12, 25-65.

Fullard, H. J. AND BelwoOd, J. J. (1988). The echolocation assemblage: Acoustic ensembles in a neotropical habitat. In Animal Sonar (ed. P. E. Nachtigall and P. W. B. Moore), pp. 639-643. New York, London: Plenum Press.

Gourevitch, G. (1987). Binaural hearing in land mammals. In Directional Hearing. (ed. W. A. Yost, and G. Gourevitch), pp. 226-246. Heidelberg, Berlin: Springer.

Griffin, D. R. And Novick, A. (1955). Acoustic orientation of neotropical bats. J. exp. Zool. 130, 251-300.

GRINNELL, A. D. (1963). The neurophysiology of audition in bats. Directional location and binaural interaction. J. Physiol., Lond. 167, 97-113.

GrinNELL, A. D. (1970). Comparative auditory physiology of neotropical bats employing different echolocation signals. Z. vergl. Physiol. 68, 117-153.

GRINNELL, A. D. AND SCHNITZLER, H.-U.(1977). Directional sensitivity of echolocation in the Horseshoe Bat, Rhinolophus ferrumequinum. II. Behavioral directionality of hearing. J. comp. Physiol. 116, 63-76.

Guppy, A. AND COLES, R. B. (1988a). Acoustical aspects of hearing and echolocation in bats. In Animal Sonar (ed. P. E. Nachtigall and P. W. B. Moore), pp. 289-294. New York, London: Plenum Press. 
Guppy, A. And COles, R. B.(1988b). Acoustical and neural aspects of hearing in the Australian gleaning bats, Macroderma gigas and Nyctophilus gouldi. J. comp. Physiol. A 162, 653-668.

Gustafson, Y. AND SCHNITZLeR, H.-U.(1979). Echolocation and obstacle avoidance in the hipposiderid bat Asselia tridens. J. comp. Physiol. A 131, 161-167.

Habersetzer, J. (1981). Adaptive echolocation sounds in the bat Rhinopoma hardwickei. J. comp. Physiol. 144, 559-566.

Henson, O. W., Bishop, A., Keating, A. and Kobler, J. (1987). Biosonar imaging of insects by Pteronotus parnellii, the Mustached Bat. Natl Geog. Res. 3, 82-101.

Howell, D. J. (1974). Acoustic behavior and feeding in Glossophagine bats. J. Mammal. 55, 293-308.

IRviNE, D. R. G.(1987). Interaural intensity differences in the cat: Changes in sound pressure level at the two ears associated with azimuthal displacements in the frontal horizontal plane. Hearing Res. 26, 267-286.

JEN, P. H.-S. (1980). Coding of directional information by single neurons in the S-segment of the FM bat, Myotis lucifugus. J. exp. Biol. 87, 203-216.

JEN, P. H.-S. AND CHEN, D. (1988). Directionality of sound pressure transformation at the pinna of echolocating bats. Hearing Res. 34, 101-118.

JeN, P. H.-S. AND Suthers, R. A. (1982). Responses of inferior collicular neurons to acoustic stimuli in certain FM and CF FM Paleotropical bats. J. comp. Physiol. A 146, 423-434.

KICK, S. A. (1982). Target detection by the echolocating bat Eptesicus fuscus. J. comp. Physiol. 145, $431-435$.

KOBER, R. AND SCHNITZLER, H.-U. (1990). Information in sonar echoes of fluttering insects available for echolocating bats. J. acoust. Soc. Am. 87, 882-896.

Lawrence, B. D. AND Simmons, J. A. (1982). Measurements of atmospheric attenuation at ultrasonic frequencies and the significance for echolocating bats. J. acoust. Soc. Am. 71, 585-590.

LEONARD, M. L. AND FENTON, M. B. (1984). Echolocation calls of Euderma maculatum (Vespertilionidae), use in orientation and communication. J. Mammal. 65, 122-126.

LONG, G. AND SCHNTTZLER, H.-U. (1975). Behavioral audiograms from the bat Rhinolophus ferrumequinum. J. comp. Physiol. 100, 211-219.

MARTIN, R. L. AND WEBSTER, W. R. (1989). Interaural sound pressure level differences associated with sound-source locations in the frontal hemifield of the domestic cat. Hearing Res. 38, 289-302.

Mills, A. W.(1960). Lateralization of high-frequency tones. J. acoust. Soc. Am. 32, 132-134.

Mogdans, J., Ostwald, J. And Schnitzler, H.-U. (1988). The role of pinna movement for the localization of vertical and horizontal obstacles in the greater horseshoe bat, Rhinolophus ferrumequinum. J. acoust. Soc. Am. 84, 1676-1679.

NeuweILER, G. (1970). Neurophysiologische Untersuchungen zum Echoortungssystem der Grossen Hufeisennase Rhinolophus ferrumequinum Schreber, 1774. Z. vergl. Physiol. 67, 273-306.

NeuweILER, G.(1984). Foraging, echolocation and audition in bats. Naturwissenschaften 71, 446-455.

Neuweiler, G. And Fenton, M. B. (1988). Behaviour and foraging ecology of echolocating bats. In Animal Sonar (ed. P. E. Nachtigall and P. W. B. Moore), pp. 535-549. New York, London: Plenum Press.

Neuweiler, G., Singh, S. And Sripathi, K. (1984). Audiograms of a South Indian bat community. J. comp. Physiol. A 154, 133-142.

OBRist, M. K. (1989). Individuelle Variabilität der Echoortung, Vergleichende Freilanduntersuchungen an vier vespertilioniden Fledermausarten Kanadas. Dissertation, Ludwig-Maximilians-Universität, München.

Peff, T. C. And Simmons, J. A.(1971). Horizontal-angle resolution by echolocating bats. J. acoust. Soc. Am. 51, 2063-2065.

PETERs, A. (1987). Analyse der Frequenzrepräsentation im Innenohr der echoortenden Fledermaus Hipposideros lankadiva, Eine HRP-S tudie. Diplomarbeit an der Technischen Universität München.

Poussin, C. AND SCHLEgel, P. (1984). Directional sensitivity of auditory neurons in the superior colliculus of the bat, Eptesicus fuscus, using free field sound stimulation. J. comp. Physiol. A 154, 253-261.

Pye, J. D. (1980a). Echolocation signals and echoes in air. In Animal Sonar Systems (ed. R. G. Busnel and J. F. Fish), pp. 309-354. New York: Plenum Press.

PyE, J. D. (1980b). Adaptiveness of echolocation signals in bats. Flexibility in behaviour and evolution. Trends Neurosci. 10, 232-235.

Pye, J. D. and Roberts, L. H. (1970). Ear movements in a Hipposiderid bat. Nature 225, 285-286. 
Roeder, K. D.(1970). Episodes in insect brains. Am. Sci. 58, 378-389.

Roverud, C. R. AND GrinNell, A. D. (1985). Frequency tracking and Doppler shift compensation in response to an artificial CF/FM echolocation sound in the CF/FM bat Noctilio albiventris. J. comp. Physiol. A 156, 471-475.

SCHLEGEL, P. (1977a). Calibrated earphones for the echolocating bat, Rhinolophus ferrumequinum. J. comp. Physiol. 118, 353-356.

SCHLEGEL, P. (1977b). Directional coding by binaural brainstem units of the CF-FM bat Rhinolophus ferrumequinum. J. comp. Physiol 118, 327-352.

SCHLEGEl, P. A., JEN, P. H.-S. AND SINGH, S. (1988). Auditory spatial sensitivity of inferior collicular neurons of echolocating bats. Brain Res. 456, 127-138.

SCHMidt, S., TÜRKE, B. AND Vogler, B. (1984). Behavioural audiogram from the bat, Megaderma lyra (Geoffroy, 1810; Microchiroptera). Myotis 21-22, 62-66.

Schmidt, U., Schlegel, P., SchweIzer, H. And Neuweiler, G. (1991). Audition in vampire bats, Desmodus rotundus. J. comp. Physiol. A 168, 45-51.

SChNitZleR, H.-U. And GRINNELl, A. D.(1977). Directional sensitivity of echolocation in the Horseshoe Bat, Rhinolophus ferrumequinum. I. Directionality of sound emission. J. comp. Physiol. 116, 51-61.

Shimozawa, T., SugA, N., Hendler, P. And SChuetze, S.(1974). Directional sensitivity of echolocation system in bats producing frequency-modulated signals. J. exp. Biol. 60, 53-69.

Simmons, J. A., Howell, D. J. And SugA, N. (1975). Information content of bat sonar echoes. Am. Sci. 63, 204-215.

Simmons, J. A., Kick, S. A. And Lawrence, B. D.(1984). Echolocation and hearing in the mouse-tailed bat, Rhinopoma hardwickei, acoustic evolution of echolocation in bats. J. comp. Physiol. A 154, 347-356.

Simmons, J. A., Kick, S. A., Lawrence, B. D., Hale, C., BaArd, C. and Escudié, B. (1983). Acuity of horizontal angle discrimination by the echolocating bat, Eptesicus fuscus. J. comp. Physiol. 153, $321-330$.

Simmons, J. A., Lavender, W. A., Lavender, B. A., Childs, J. E., Hulebak, K., Rigden, M. R., Sherman, J., Woolman, B. And O'Farrell, M. J. O. (1978). Echolocation by free-tailed bats (Tadarida). J. comp. Physiol. 125, 291-299.

Simmons, J. A. And O'Farrell, M. J. (1977). Echolocation in the long-eared bat, Plecotus phyllotis. J. comp. Physiol. 122, 201-214.

Simmons, J. A. AND SteIn, R. A. (1980). Acoustic imaging in bat sonar: Echolocation signals and the evolution of echolocation. J. comp. Physiol. 135, 61-84.

Suthers, R. A. (1988). The production of echolocation signals by bats and birds. In Animal Sonar (ed. P. E. Nachtigall and P. W. B. Moore), pp. 23-45. New York, London: Plenum Press.

Suthers, R. A. And Summers, C. A. (1980). Behavioral audiogram and masked thresholds of the megachiropteran echolocating bat, Rousettus. J. comp. Physiol. 136, 227-333.

TutTLE, M. D. AND Ryan, M. J. (1982). The role of synchronized calling, ambient light and ambient noise, in anti-bat-predator behavior of a treefrog. Behav. Ecol. Sociobiol. 11, 125-131.

TutTle, M. D., Ryan, M. J. And BelwoOd, J. J.(1985). Acoustical resource partitioning by two species of phyllostomid bats (Trachops cirrhosus and Tonatia sylvicola). Anim. Behav. 33, 1369-1371.

W AKEFORD, O. S. AND RobINSON, D. E.(1974). Lateralization of tonal stimuli by the cat. J. acoust. Soc. Am. 55, 649-652.

Wenstrup, J. J. (1984). Auditory sensitivity in the fish-catching bat, Noctilio leporinus. J. comp. Physiol. A 155, 91-101.

WitZKE, P. (1989). Acuity of pure-tone lateralization by the Indian False Vampire, Megaderma lyra. (Microchiroptera, Megadermatidae). In European Bat Research 1987 (ed. V. Hanák, I. Horácek and J. Gaisler), pp. 281-286. Praha: Charles University Press.

Woodsworth, G. C., Bell, G. And Fenton, M. B. (1981). Observation of the echolocation, feeding behaviour and habitat use of Euderma maculatum (Chiroptera, Vespertilionidae) in south central British Columbia. J. Zool., Lond. 59, 1099-1102. 